\title{
The effect of anisotropic microstructure on the crack growth and fatigue overload behaviour of ultrafine grained nickel
}

DOI:

10.1016/j.actamat.2019.11.024

\section{Document Version}

Accepted author manuscript

Link to publication record in Manchester Research Explorer

Citation for published version (APA):

Zhang, W., Simpson, C., Leitner, T., Zhang, X., Pippan, R., \& Withers, P. (2020). The effect of anisotropic microstructure on the crack growth and fatigue overload behaviour of ultrafine grained nickel. Acta Materialia, 184, 225-240. https://doi.org/10.1016/j.actamat.2019.11.024

\section{Published in:}

Acta Materialia

\section{Citing this paper}

Please note that where the full-text provided on Manchester Research Explorer is the Author Accepted Manuscript or Proof version this may differ from the final Published version. If citing, it is advised that you check and use the publisher's definitive version.

\section{General rights}

Copyright and moral rights for the publications made accessible in the Research Explorer are retained by the authors and/or other copyright owners and it is a condition of accessing publications that users recognise and abide by the legal requirements associated with these rights.

\section{Takedown policy}

If you believe that this document breaches copyright please refer to the University of Manchester's Takedown Procedures [http://man.ac.uk/04Y6Bo] or contact uml.scholarlycommunications@manchester.ac.uk providing relevant details, so we can investigate your claim.

\section{OPEN ACCESS}




\section{The effect of anisotropic microstructure on the crack growth and fatigue overload}

\section{behaviour of ultrafine-grained nickel}

Wen Zhang a , Christopher A. Simpson ${ }^{\mathrm{b}}$, Thomas Leitner ${ }^{\mathrm{c}, \mathrm{d}}$, Xun Zhang ${ }^{\mathrm{e}}$, Reinhard Pippan ${ }^{\mathrm{c}, \mathrm{d}}$, Philip J. Withers ${ }^{a *}$

${ }^{a}$ Henry Royce Institute, Department of Materials, The University of Manchester, Manchester, United Kingdom, M13 9PL, UK

${ }^{\mathrm{b}}$ Department of Mechanical Engineering, University of Bristol, Queen's Building, University Walk, Bristol, BS8 1TR UK

${ }^{\mathrm{c}}$ Department of Materials Physics, Montanuniversitaet Leoben, Austria

${ }^{\mathrm{d}}$ Erich Schmid Institute of Materials Science, Austrian Academy of Sciences, Leoben, Austria

${ }^{\mathrm{e}}$ Department of Engineering Science, University of Oxford, Parks Road, Oxford, OX1 3PJ, UK

\section{Graphical abstract}
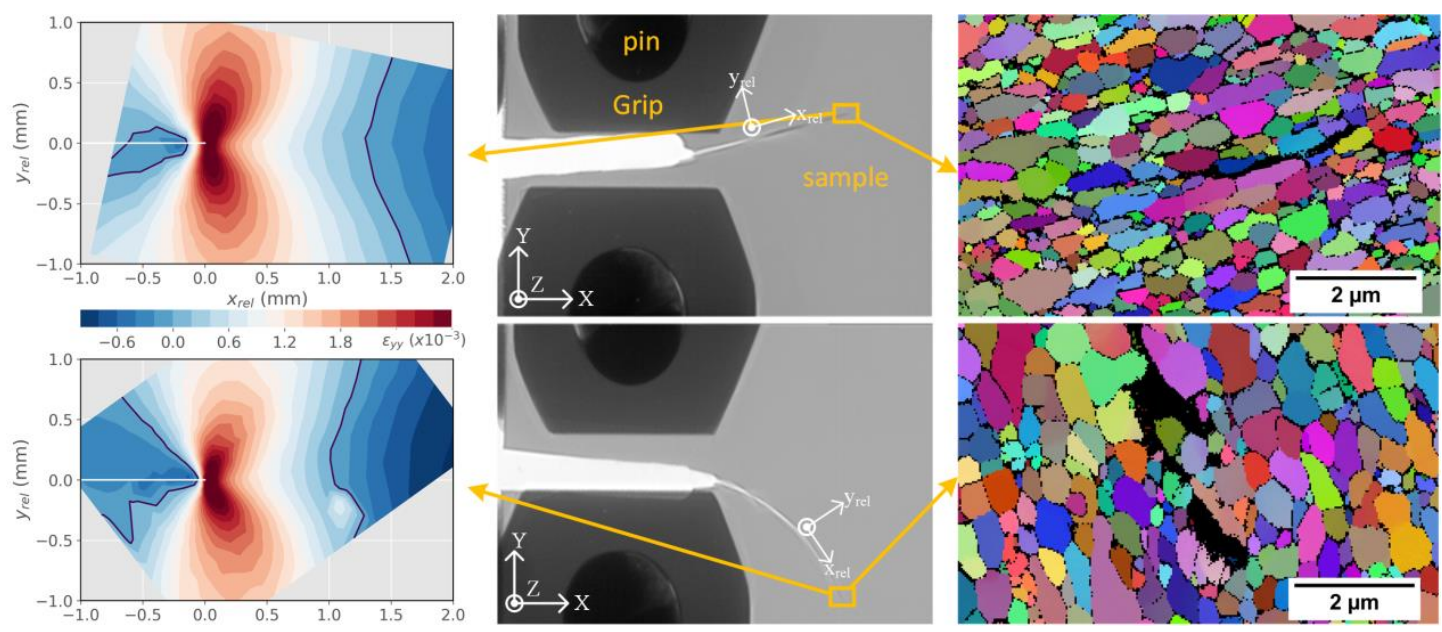

\section{Abstract}

Changes in crack growth rate associated with overload events during fatigue are poorly understood, especially for materials with anisotropic microstructures. Here overload fatigue tests are reported for compact tension samples cut in two different orientations from high pressure torsion disc samples. During growth the crack planes reoriented either slightly, or significantly, to align with the elongated grain structure leading to low, and high, levels of mixed mode fatigue loading respectively. In both cases the ultrafine grained microstructure led to macroscopically flat crack faces. The fatigue crack growth rate was around 3.4 times slower for the case with the high mode II component than for the low. A $100 \%$ overload was then introduced and synchrotron X-ray diffraction and digital image correlation (DIC) were 
applied in-situ to map the bulk crack-tip elastic strain field (plane strain) and surface displacement field (plane stress) respectively prior to, during and after overload. The high mode II case displayed a larger degree of retardation after overload. Residual stress and plasticity-induced crack closure were found to be the primary causes for the retardation as the crack grows into the overload plastic zone. Significant crack face contact was observed for the high mode II case along with significant levels of compressive stress transferred across the crack faces at minimum load. Compared with conventional (coarse) grain $\mathrm{Ni}$, the ultrafine grained Ni is less retarded by overload, because of its relatively flatter crack path and higher yield stress and thus less plasticity and residual stress induced closure.

Keywords: high pressure torsion, nanocrystalline, plasticity-induced crack closure, crack deflection, surface roughness

\section{Introduction}

With the development of material processing techniques, such as severe plastic deformation (SPD) [1], ultrafine grained (UFG) materials with grain sizes in the submicron range have attracted attention, both from a scientific and engineering point of view. Both their grain size and elongated grain morphology arising from the processing method mean that their mechanical behaviour is expected to be quite different from conventional materials, especially under fatigue where microstructural effects can play a strong role. In practice load bearing structures and components rarely experience constant amplitude fatigue loading during service. Overloads (OL) tend to retard, while underloads accelerate, fatigue crack growth (FCG) [2]. Many explanations for overload retardation have been proposed, such as crack closure, compressive residual stress, crack deflection and crack-tip blunting [3]. However, the relative importance of these retardation mechanisms is still a subject of debate, especially when the effects of grain size and orientation are taken into account.

Plasticity-induced crack closure [4-8], which results from the permanent residual deformation in the wake of crack tip, is believed to be one of the most important retardation mechanisms after overload. Crack closure can occur during baseline fatigue, but is enhanced after overload because of the larger plastic stretch at the overload location. The overload-induced plastic stretch leads to a misfit between it and the rest of the elastically deformed material during unloading from overload. As a result, a compressive residually stressed zone forms ahead of the crack. Crack face contact tends not to occur immediately after overload because the stretch means the crack faces are open at minimum load $\left(P_{\min }\right)$. As the crack grows beyond the overload position, the plastic misfit gives rise to premature crack 
face contact during unloading (crack closure), and hence a decrease in the effective SIF range, $\Delta K^{\text {eff }}$. Consequently, in fatigue, plasticity-induced crack closure and residual stress induced closure are related since the misfit generated causes a plastic ridge and generates compressive stresses that tend to hold the crack shut at zero applied load. As the crack grows beyond the compressive residual stress field crack face contact can still occur in the region of the overload if $P_{\min }$ is sufficiently low. This is referred to as discontinuous crack closure [9] and the crack faces tractions hold the crack open, limiting the drop in stress intensity at $P_{\min }$, i.e. $K_{\min }^{\text {eff }}>K_{\min }^{\text {nom }}$.

Plasticity induced closure has been observed in microcrystalline materials (grain size larger than $1 \mu \mathrm{m}$ ) by digital image correlation [10] and by the compliance technique using a pin microgauge [11] under plane stress conditions, and by synchrotron X-ray diffraction (SXRD) under plane strain conditions [12]. However, little evidence of crack closure was observed in ultrafine grained AA5091 aluminium alloy under plane strain conditions, possibly because of its very small overload plastic zone [13]. This might also be due to the fact that plane strain is more likely to restrict the occurrence of plasticity-induced crack closure than plane stress $[14,15]$.

The residual stress (RS) impedes the crack opening and reduces the mean stress during cyclic loading $[3,16,17]$. Unless the crack faces touch during unloading the RS is expected to have no effect on the stress intensity range. Depending on the applied $R$ ratio, the compressive residual stress may be sufficient for the crack faces to touch over part of the loading cycle once the crack has started to propagate after overload, leading to residual stress induced closure.

Roughness-induced crack closure [18-20] is caused by a misfit between the fractured surfaces. The crack can propagate transgranularly or intergranularly or both, which leads to a serrated or faceted crack morphology. Typically a small grain size leads to a relatively flat crack that is unfavorable for roughness-induced closure whereas a large grain size induces a more tortuous crack that promotes closure [21].

Crack deflection [3] can also play a very important role in FCG retardation. Deflection of the crack path from its nominal propagation direction enhances the resistance to FCG by reducing the effective stress intensity factor range. Under Mode I loading condition, the crack driving force of a deflected crack is smaller than that of a straight crack with the same projected length subjected to the same far-field cyclic load. While the effective Mode I stress intensity is reduced due to deflection, the local Mode II stress intensity is increased. This can lead to relative movement of the crack surfaces along the crack propagation direction and hence promote roughness-induced crack closure. Leitner et al. [22] observed that an elongated 
microstructure that is perpendicular to the crack propagation direction induces a large deflection angle and improves the resistance to the FCG whereas an elongated microstructure that approximately aligned to the crack propagation direction leads to a small deflection angle and facilitates FCG.

In summary, there are many mechanisms contributing to overload retardation under different scenarios. A sole mechanism is rarely sufficient to explain the overload effects. To date most of the work has focused on coarse-grained materials. Here we address the following unresolved questions for ultrafine grained materials: (i) Is the overload effect evident under plane strain conditions? (ii) What are the dominant mechanisms for overload retardation for UFG materials? (iii) Will the overload retardation be affected by the elongated grain shape similarly to the baseline fatigue case [23]?

To address these questions, fatigue overload experiments on two UFG Ni samples with different grain elongation directions under plane strain conditions were conducted in-situ on the beamline I12-JEEP at the UK's national synchrotron science facility, the Diamond Light Source (DLS). Digital image correlation (DIC) was used to measure the displacement field on the sample surface, from which the crack opening displacement $(\triangle C O D)$ and stress intensity factor range were determined. Synchrotron X-ray diffraction (SXRD) was used to probe the through thickness averaged strain distribution in the vicinity of the crack tip, from which the residual stress and stress intensity factor were estimated as a function of crack growth past the OL position. In addition, SEM fractography has been used to investigate the extent of crack face contact and electron back scattered diffraction (EBSD) of cross-sections to characterize the elongated microstructure and the deflected crack growth paths. Crack face surface roughness has also been compared between the two different samples.

\section{Material and experimental methods}

\subsection{Material and samples}

The UFG material was manufactured from $99.99 \%$ pure nickel by high pressure torsion (HPT) [24] giving a yield stress $\sigma_{y} \sim 800 \mathrm{MPa}$ [23]. Compact tension (CT) samples were cut in the AT and TR orientations as shown in Fig. 1a having the geometry shown in Fig. 1b. The dimensions for the CT specimens are given in Table 1. In both cases the crack growth direction deflected; for the AT sample by $\sim 12^{\circ}$ (see Fig 1c) and in the TR case more significantly by $\sim 50^{\circ}$ (see Fig 1d). Consequently for ease of reference these samples are referred to as the low $k_{I I}$ and then high $k_{I I}$ samples respectively in this paper. 
Table 1 CT specimen dimensions and cyclic loading conditions for the two samples.

\begin{tabular}{lll}
\hline & UFG Ni AT & UFG Ni TR \\
\hline Width, $W(\mathrm{~mm})$ & 5.22 & 5.30 \\
Thickness, $B(\mathrm{~mm})$ & 1.48 & 1.20 \\
Load, $P(\mathrm{~N})$ & $20-200$ & $16.6-165.6$ \\
Overload, $P_{\mathrm{OL}}(\mathrm{N})$ & 400 & 330 \\
Overload plastic zone, $r_{\mathrm{OL}}(\mu \mathrm{m})$ & 340 & 330 \\
\hline
\end{tabular}

Note: $r_{O L}$ is estimated by Irwin's model under plane stress conditions $r_{O L}=\frac{1}{\pi}\left(\frac{k_{O L}}{\sigma_{y}}\right)^{2}$ [25].

(a)
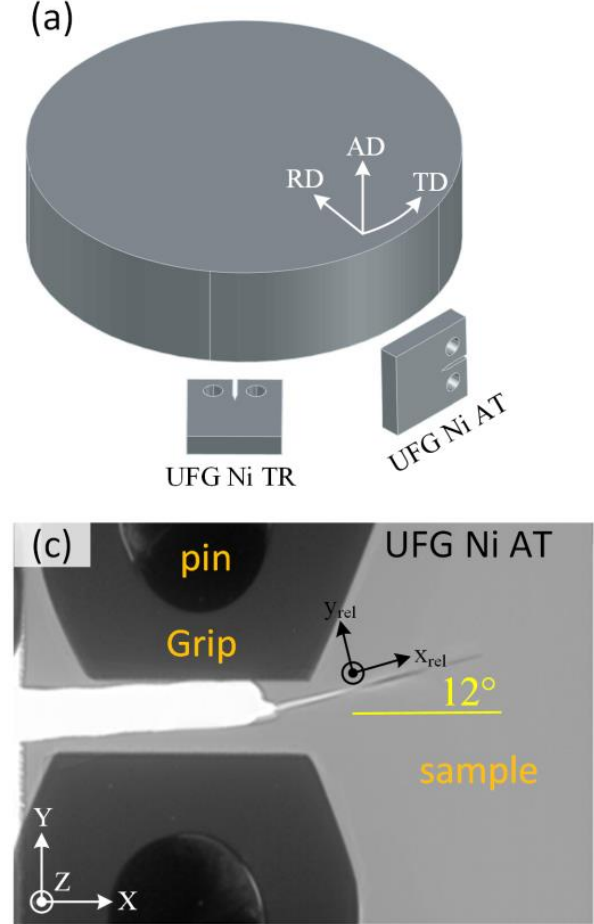
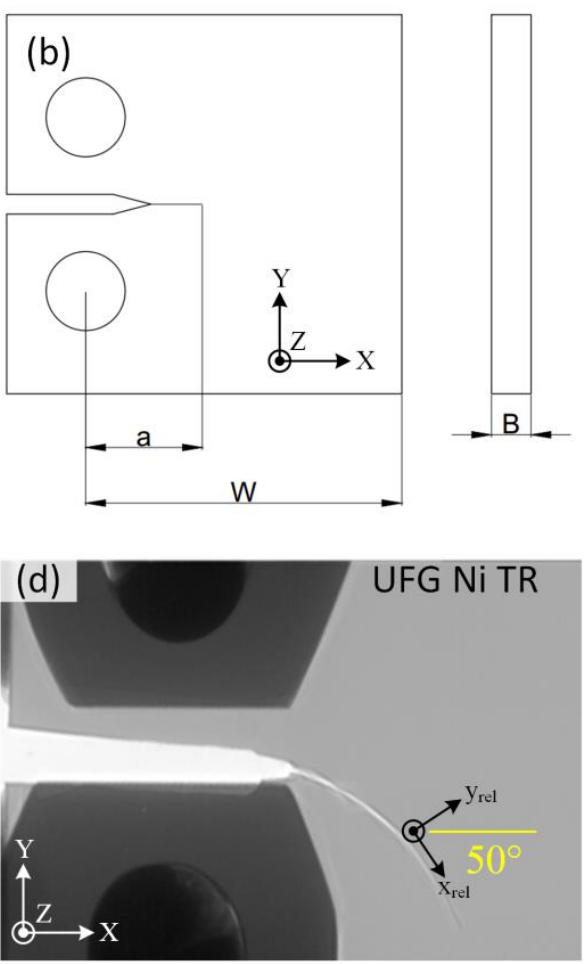

Fig. 1. (a) Schematic showing the orientation of the CT specimens extracted from the HPT discs. (b) CT specimen geometry (see Table 1). Radiographs indicating that crack path reorientation took place for (c) the AT $\left(\sim 12^{\circ}\right)$ and (d) TR $\left(\sim 50^{\circ}\right)$ samples. The coordinate systems representing the lab frame $(X, Y)$ and for the rotated crack-tip frame $\left(x_{\text {rel }}, y_{\text {rel }}\right)$ are also shown.

\subsection{Experimental setup and fatigue tests}

Fig. 2 shows the experimental configuration for the in-situ fatigue overload tests on beamline I12:JEEP at the Diamond Light Source. A $3 \mathrm{kN}$ BOSE fatigue rig was mounted on the beamline sample table. A DIC camera with two $\times 2$ teleconverters was fixed to a stepper motor such that it could be moved into the line of the beam (with the beam off) to image the 
sample. The X-ray diffraction and imaging signals were collected using a large $2 \mathrm{D}$ area diffraction detector (Thales Pixium RF4343) and high-resolution imaging camera (1.3 $\mu \mathrm{m} \times$ $1.3 \mu \mathrm{m} /$ pixel) respectively that could each be moved into the beam. This setup enables DIC, $\mathrm{X}$-ray radiography and diffraction measurements at each fatigue stage under the same loading levels.

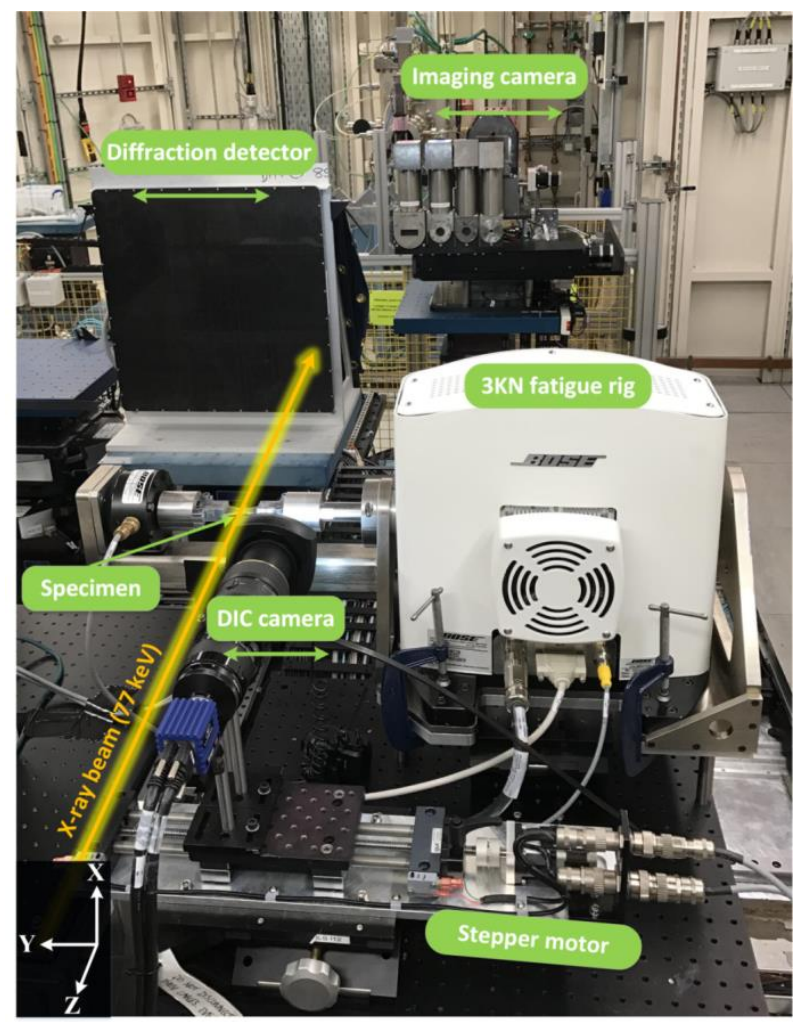

Fig. 2. Setup for the in-situ fatigue overload tests with digital image correlation, monochromatic X-ray diffraction and radiography on beamline I12-JEEP at diamond light source. The coordinate system for the lab frame $(X, Y, Z)$ is shown in the figure.

The baseline fatigue was conducted under constant loading amplitude (see Table 1) at a frequency of $40 \mathrm{~Hz}$ at $R=0.1\left(P_{\min } / P_{\max }=0.1\right)$. A $100 \%$ overload $\left(P_{O L}=2 P_{\max }\right)$ was applied when the crack length $(a)$ was around $2 \mathrm{~mm}$. Slightly different loads were applied in each case such that the same stress conditions and similar nominal SIF range $\left(\Delta K^{\text {nom }}\right)$ were experienced by the AT (low $k_{I I}$ ) and TR (high $k_{I I}$ ) samples at the overload position. The overload plastic zone, $r_{O L}$, for both samples were evaluated according to Irwin's model and listed in Table 1. As the crack-tip is assumed to be at the center of the plastic zone by Irwin's model [25], the distance from the edge of the overload plastic zone to the crack tip in the crack propagation direction should be $r_{O L} / 2$.

Diffraction measurements were conducted at various stages through the fatigue experiment, namely 1 cycle before overload, during overload, and after an additional 1, 1000, 7200, 19000, 
31000 cycles after overload (denoted by OL-1, OL, OL+1, OL+1000, OL+7200, OL+19000 and OL+31000 respectively). At each stage, the strain field was sampled at the maximum load, $P_{\max }$, and then at $0.5 P_{\max }, 0.4 P_{\max }, 0.3 P_{\max }, 0.2 P_{\max }$ and $P_{\min }$.

A camera was used with two $\times 2$ teleconverters giving a field of view of $3.25 \times 3.25 \mathrm{~mm}^{2}$ and a pixel size of $1.59 \mu \mathrm{m}$. This setup was used to track the crack length and to acquire the crack-tip displacement field at specific numbers of fatigue cycles including those also mapped by diffraction.

\subsection{Synchrotron X-ray diffraction measurements}

A monochromatic X-ray beam of $76.8 \mathrm{keV}$ energy was used at Diamond Light Source (DLS) on the I12:JEEP beamline to map the elastic strain field around the crack-tip before, during and after overload. Diffraction rings representing different $(h k l)$ lattice planes from (111) to (400) were recorded by the $2 \mathrm{D}$ area detector. In general, each lattice plane family exhibits a different response to the applied loading [26]. These stresses arise in the elastic regime because the single crystal stiffness of each lattice plane is different and in the plastic regime because slip occurs on preferred slip planes and directions, generating intergranular stresses. Some lattice planes are more affected by the intergranular stresses than others. For an FCC structured material such as nickel, (311) is one of the lattice planes that are least affected by the intergranular stresses [27]. As a result it was selected as being representative of the continuum behaviour of the material.

The (311) diffraction ring was 'caked' into 36 segments using the DAWN [28] software developed by DLS. When stress is applied, the Debye-Scherrer rings become distorted to ellipses on the detector [29]. The change in radius reflects the variation in the scattering angle, $2 \theta^{h k l}$, which can be used to determine the in-plane elastic strain components (see Fig. 3) using:

$$
\varepsilon^{h k l}=\frac{d^{h k l}-d_{0}^{h k l}}{d_{0}^{h k l}}=-\cot \theta^{h k l}\left(\theta^{h k l}-\theta_{0}^{h k l}\right)
$$

where $d_{0}^{h k l}$ is the stress-free lattice spacing of the (hkl) plane and $d^{h k l}$ is the measured spacing. There are many methods to determine the stress-free $d_{0}$ value [30]. Here $d_{0}$ is determined at a location that is far away from the crack, namely close to the corner on the tested samples prior to loading. Both the intensity and narrow width of the diffraction peaks mean that the peak position can be measured very precisely [31]. Furthermore the fine grain size means that very many grains are sampled by the diffraction peaks such that the point to point scatter is very low too (see Fig. 3b). 

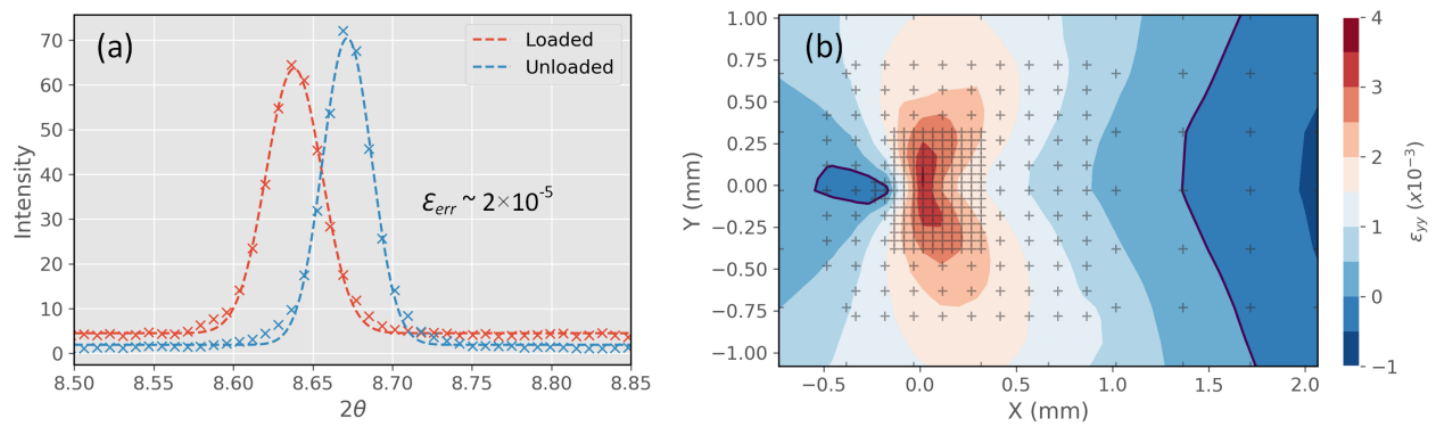

Fig.3. (a) Representative (311) Bragg diffraction peaks for the determination of elastic strains. The dashed lines indicate the best fit for a Gaussian refinement. The uncertainty of the peak position is used to evaluate the uncertainty in strains $\left(\sim 2 \times 10^{-5}\right)$. (b) Unsmoothed elastic strain field in the $Y$ direction (indicated in Fig. 1a) estimated by diffraction peak shifting for the AT (low $k_{I I}$ ) sample at $P_{O L}$. The cross symbols show the original diffraction measurement positions.

In view of the fact that the crack plane has deflected and is therefore no longer normal to the applied load, the coordinate space was rotated (from $(X, Y)$ to $\left.\left(x_{r e l}, y_{\text {rel }}\right)\right)$ as shown in Fig. 1c) and d) and the strain field is shown in Fig. 4a for the low $k_{I I}$ sample. The stress field in the crack opening direction was then calculated using Eq. 2. Since no defining slits are used, the strain is sampled over the whole specimen thickness, most of which is representative of plane strain conditions (as discussed in section 3.2). Therefore, a plane strain condition was assumed to infer the stress state from the two in-plane strain components $\left(\varepsilon_{x x}^{h k l}\right.$ and $\left.\varepsilon_{y y}^{h k l}\right)$. The stress in the crack opening direction, $\sigma_{y y}$, can then be calculated using the following equation:

$$
\sigma_{y y}=\frac{E^{h k l}}{\left(1+v^{h k l}\right)\left(1-2 v^{h k l}\right)}\left(v^{h k l} \varepsilon_{x x}^{h k l}+\left(1-v^{h k l}\right) \varepsilon_{y y}^{h k l}\right)
$$

where $E^{h k l}$ and $v^{h k l}$ are the respective diffraction elastic modulus and Poisson's ratio associated with the $(h k l)$ lattice plane. In our case (311) was monitored having $E^{311}=185 \mathrm{GPa}$ and $v^{311}=$ 0.33 as per the Kroner polycrystal modelling scheme.

At each fatigue stage, a fine map just around the crack-tip and coarse maps over the far field region were acquired at $P_{\max }$ and $P_{\min }$. The beam size was $50 \times 50 \mu \mathrm{m}^{2}$ with a spacing between measurements of $50 \mu \mathrm{m}$ for the fine map. A $100 \times 100 \mu \mathrm{m}^{2}$ beam with spacings of $150 \mu \mathrm{m}$ and $300 \mu \mathrm{m}$ were applied for the coarse maps as shown in Fig. 3b. For reasons of time efficiency, line profiles comprising a band of fine lines and coarse lines with spacings similar to the maps, were acquired at intermediate loading levels. The strain calculation and the merging of the fine and coarse maps was then undertaken using the pyXe strain analysis package [32]. 

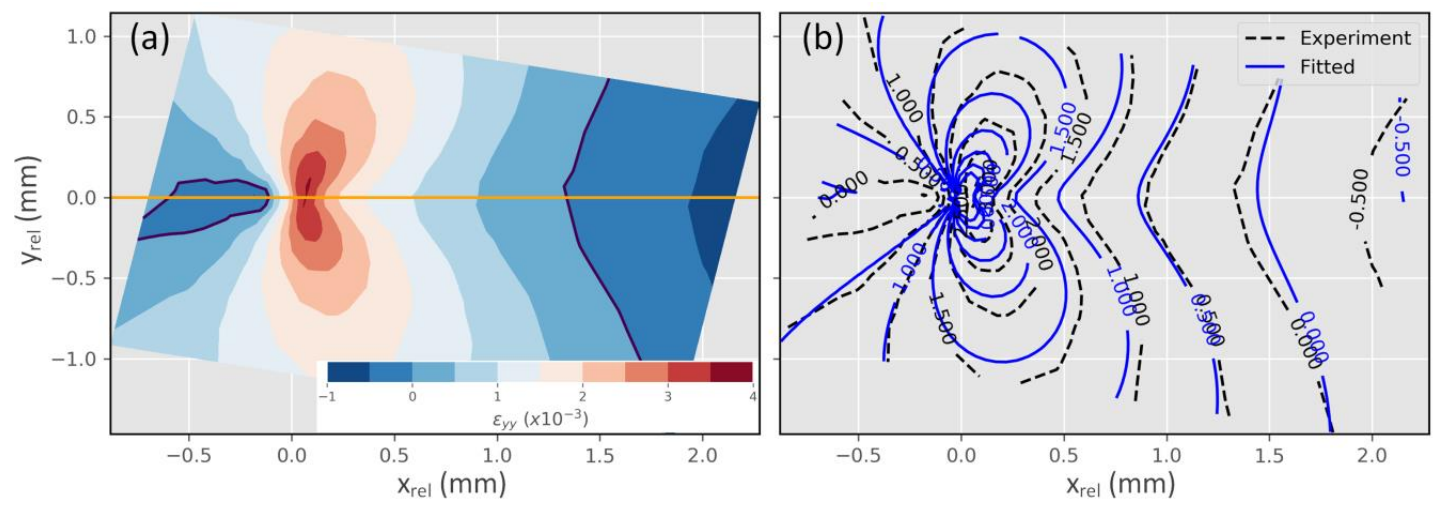

Fig. 4. Inferring the stress intensity factor from the elastic strain field for the low $k_{I I}$ sample at $P_{O L}$ measured by diffraction in the crack opening direction using the rotated relative coordinate system $\left(x_{r e l}, y_{\text {rel }}\right)$. In the relative coordinates the origin represents the current crack-tip position. (a) Map rotated such that the crack is horizontal. The orange line represents the crack faces and propagation direction. (b) Comparison of the elastic strain field in the crack opening direction between the experimental and fitted results.

By fitting the crack-tip elastic strain field in the crack opening direction, the effective stress intensity factor (SIF) that characterizes the stress state around the crack tip was determined before, during and after OL using Williams' approach [25] to best-fit the strains in the crack opening direction assuming plane strain conditions:

$$
\begin{gathered}
\frac{E}{1+v} \varepsilon_{y y}=\sum A_{n} \frac{n}{2} r^{\frac{n}{2}-1}\left\{\left[2(1-2 v)-(-1)^{n}-\frac{n}{2}\right] \cos \left(\frac{n}{2}-1\right) \theta+\left(\frac{n}{2}-1\right) \cos \left(\frac{n}{2}-3\right) \theta\right\}+ \\
\sum B_{n} \frac{n}{2} r^{\frac{n}{2}-1}\left\{\left[2(1-2 v)+(-1)^{n}-\frac{n}{2}\right] \sin \left(\frac{n}{2}-1\right) \theta+\left(\frac{n}{2}-1\right) \sin \left(\frac{n}{2}-3\right) \theta\right\}
\end{gathered}
$$

It should be noted that the coefficients for the first term, $A_{1}$ and $B_{1}$, are related to Mode I

SIF $k_{I}$ and Mode II SIF $k_{I I}$ respectively. $k_{I}=A_{I} \sqrt{2 \pi}$ and $k_{I I}=B_{I} \sqrt{2 \pi}$ dominate the strain field when $r \rightarrow 0$ ( $r$ is the distance from the crack tip). However, it is not reliable to utilize just the first order term when fitting a large region with a relatively large nonlinear zone around the crack tip [33]. In this research, 12 orders of the Williams power expansion were considered. Good fitting quality was achieved as shown in Fig. 4b.

\subsection{Digital image correlation}

The sample surfaces were abraded with SiC paper from 600 up to 2000 to achieve a random and fine scratch pattern. The commercial software LaVision DaVis was used to process the images. After setting numbers of fatigue cycles a sequence of images were collected during a fatigue unloading cycle and then rotated to the crack frame. All the images in each unloading sequence were correlated to the one at $P_{\min }$ to infer the displacement field. A 
small patch size was used (16×16 pixels overlapped by $75 \%)$ giving a spacing between neighbouring patches of around $6.4 \mu \mathrm{m}$. The change in crack opening displacement $(\triangle C O D)$ was determined by subtracting the crack-opening displacement of the upper and lower flanks of the crack. In each case the stress intensity factor range $(\Delta k)$ was evaluated from the displacement field in the crack opening direction using Williams' approach [34] considering mixed-mode loading:

$$
\begin{gathered}
u_{y y}=\sum A_{n} \frac{1}{2 \mu} r^{\frac{n}{2}}\left\{\left[\kappa-\frac{n}{2}-(-1)^{n}\right] \sin \left(\frac{n}{2}\right) \theta+\frac{n}{2} \sin \left(\frac{n}{2}-2\right) \theta\right\}+ \\
\sum B_{n} \frac{1}{2 \mu} r^{\frac{n}{2}}\left\{\left[\kappa-\frac{n}{2}+(-1)^{n}\right] \cos \left(\frac{n}{2}\right) \theta+\frac{n}{2} \cos \left(\frac{n}{2}-2\right) \theta\right\}
\end{gathered}
$$

In this equation, $\mu$ is the shear modulus $(\mu=E / 2(1+v))$ and $\kappa$ describes the stress state $(\kappa=(3-v) /(1+v)$ for plane stress $)$.

As for the plane stress displacement field, 12 orders of the Williams power expansion were considered to achieve high-accuracy results. Fig. 5 shows the surface displacement field in the crack opening direction. Note that the overload plastic zone estimated by Irwin's model $(\sim 330 \mu \mathrm{m})$ is a significant portion of the field of view. However, as discussed above, the distance from the edge of the plastic zone to the crack tip in the crack growth direction should be $r_{O L} / 2$ according to Irwin's assumption. Therefore, the non-linear zone does not have a significant effect on the fitting quality. This is evidenced by the good fitting results as shown in Fig. 5b and Fig. 12.
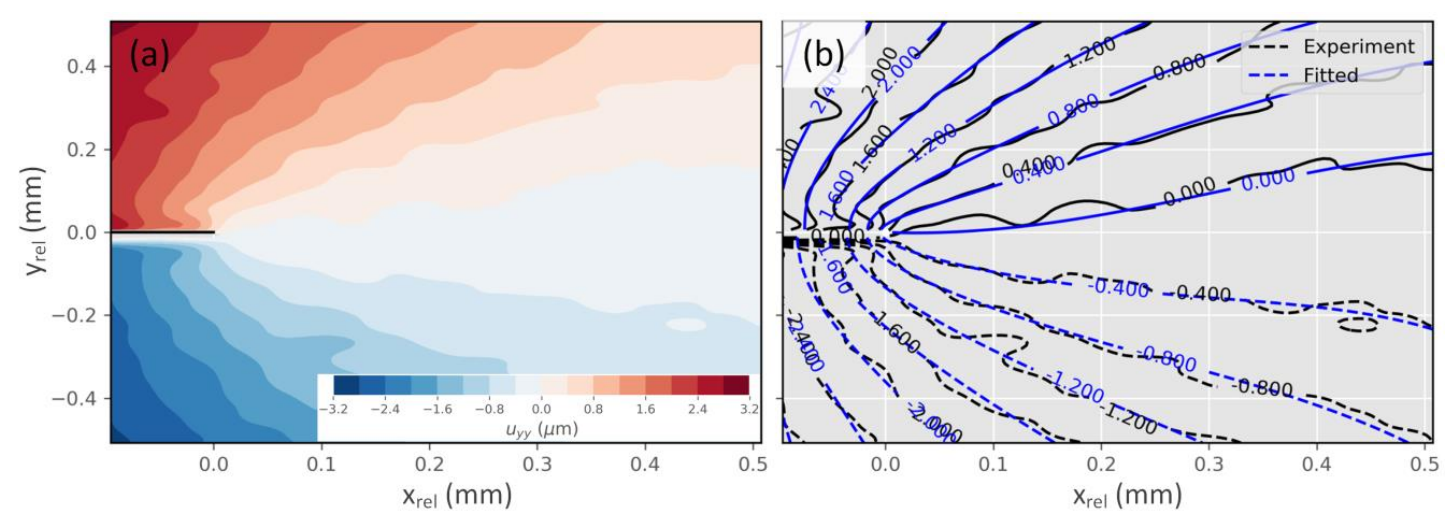

Fig. 5. Inferring the stress intensity factor from the displacement field for the low $k_{I I}$ sample at $P_{O L}$ measured by DIC in the rotated relative coordinate system. In the relative coordinates the origin represents the current crack-tip position. (a) The displacement field (in microns) in the crack opening direction. The black line indicates the crack position. (b) Comparison between the measured (black curves) and fitted (blue curves) displacement fields. 


\section{Results}

\subsection{Fatigue crack paths}

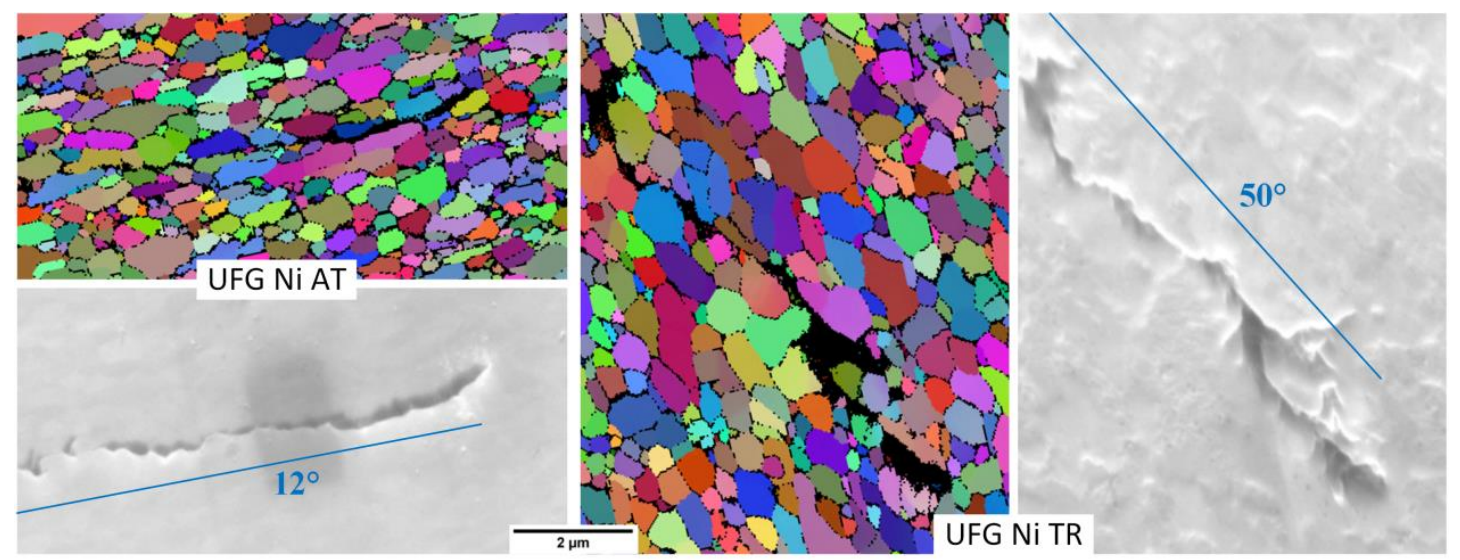

Fig. 6. Crack paths at the sample surfaces for the AT (low $k_{I I}$ ) and TR (high $k_{I I}$ ) samples revealed by scanning electron microscopy alongside electron back scattered diffraction (EBSD) mapping of the ultra-fine grains.

The EBSD maps in Fig. 6 suggest the grain size is approximately $550 \mathrm{~nm} \times 280 \mathrm{~nm}$ (along and perpendicular to the elongated direction respectively which as a result of the torsion geometry is slightly misaligned to the orientations of the HPT disc).

The deflection and reorientation of the crack paths observed in Fig. 1 is marked. It is clear from the EBSD patterns in Fig. 6 that this reorientation is governed by the anisotropic microstructure, which is slightly inclined relative to the RD-TD plane and significantly inclined relative to the RD-AD plane. Crack growth is evidently intergranular, in common with previous observations which have been explained in terms of dislocation motion, i.e. by a blunting and resharpening process where the grain boundaries serve as weak crack paths, resulting in intergranular cracking when the size of the cyclic plastic zone is in the order of the grain size [23]. This strong tendency for microstructural steering of the crack is despite the fact that in our case the cyclic plastic zone is of order $4 \mu \mathrm{m}$, which is somewhat larger than the grain size, and the fact that the grains appear to be elongated only to a relatively modest degree. However it should be borne in mind that Leitner et al. [23] found grains elongated to a few microns in length in nominally identical samples and so it is possible that the grain anisotropy here at the surface is an under-representation of that within the sample as a whole. Either way the intergranular nature of the crack path and its interaction with the grain shapes is striking in Fig. 6. 


\subsection{Fatigue crack growth results}

The nominally applied mode I stress intensity factor, $K_{I}$, for a compact tension specimen can be calculated as follows [35]:

$$
K_{I}=\frac{P}{B \sqrt{W}} \frac{(2+\alpha)}{(1-\alpha)^{1.5}}\left(0.886+4.64 \alpha-13.32 \alpha^{2}+14.72 \alpha^{3}-5.6 \alpha^{4}\right)
$$

where $\alpha=a / W$.

For all the FCG data, the uncracked ligament $(W-a)$ is larger than $(4 / \pi) /\left(K_{\max } / \sigma_{y}\right)^{2}$ so that linear elastic fracture mechanics (LEFM) can be applied. The crack length $a$ is greater than $2.5\left(K_{\max } / \sigma_{y}\right)^{2}$ so that the short crack effect is eliminated. To ensure plane strain prevails, the specimen thickness complies with the condition $B>2.5\left(K_{\max } / \sigma_{y}\right)^{2}[36]$.

The crack paths for both specimens are shown in Fig. 1. The crack for the AT sample is very straight but at an angle of $12^{\circ}$ to the plane of symmetry. For the TR sample, the crack is curved having deflected continuously to around $50^{\circ}$. Due to the large deflection angles, the local crack driving force represents a mixed-mode condition [37] given by:

$$
\begin{aligned}
& k_{I}=K_{I} \cos ^{3}(\beta / 2) \\
& k_{I I}=K_{I} \sin (\beta / 2) \cos ^{2}(\beta / 2)
\end{aligned}
$$

where $\beta$ is the deflection angle, $k_{l}$ and $k_{I I}$ are the local nominal mode I and mode II stress intensity factors, respectively. According to the energy release rate criterion, the stress intensity factor, $k$, for the crack growing at a large deflection angle can be calculated as follows [37]:

$$
k=\sqrt{k_{I}^{2}+k_{I I}^{2}}
$$

Fig. 7 shows the FCG rates in the AT (low $k_{I I}$ ) and TR (high $k_{I I}$ ) orientations. The high $k_{I I}$ sample direction has a much stronger resistance to FCG under baseline fatigue despite the crack path largely following the grain elongation direction in both cases (Fig. 6). The baseline FCG behaviour of both samples can be described by the Paris Law:

$$
\frac{d a}{d N}=C \Delta k^{m}
$$

The coefficients $C$ and $m$ for both samples are listed in Table 2. It can be seen from Table 2 and Fig. 7 that the parameter $m$ for both cases is very similar. For a better comparison of the parameter $C$ and hence the FCG rates of the two samples, the slope $m$ was represented by the average of the two values. Then the values of coefficient $C$ were re-fitted to clearly and reliably show the difference in FCG as shown in Table 2. Under the same $\Delta k$, the FCG rate for 
the high $k_{I I}$ sample is around 2.4 times slower than that for low $k_{I I}$.

Retardation is observed for both specimens after OL. It takes $\sim 3.3$ times more cycles for the high $k_{I I}$ sample to recover to the baseline FCG rate, but approximately the same extension in fatigue crack length, to return the baseline FCG rates for both samples.

Table 2 Parameters for Paris' law.

\begin{tabular}{lll}
\hline & UFG Ni (low $\left.k_{I I}\right)$ & UFG Ni (high $\left.k_{I I}\right)$ \\
\hline$C$ & $11.4 \times 10^{-10}$ & $0.91 \times 10^{-10}$ \\
$m$ & 1.56 & 2.10 \\
$C$ fitted for $m=1.83$ & $5.86 \times 10^{-10}$ & $1.72 \times 10^{-10}$ \\
\hline
\end{tabular}
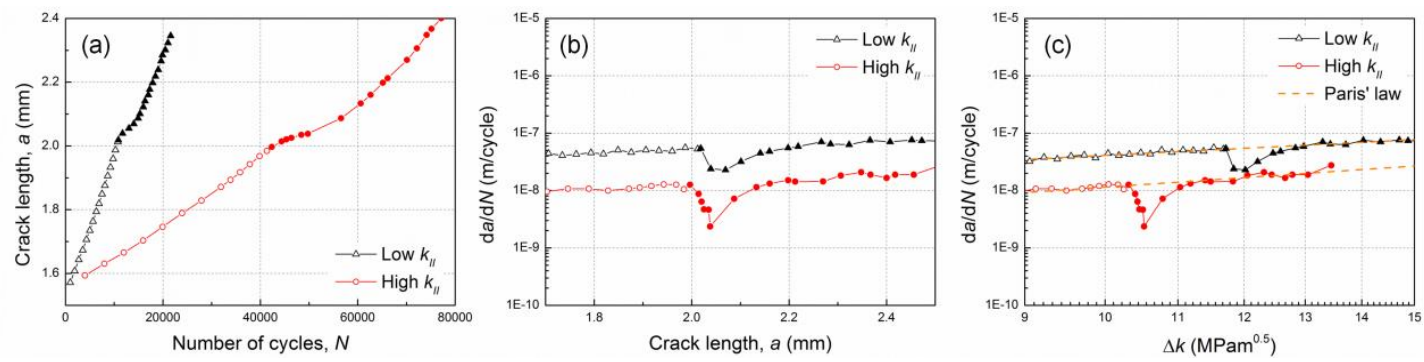

Fig. 7. Fatigue crack growth curves. (a) Variation in crack length with respect to number of cycles. (b) Variation in fatigue crack growth rate, $\mathrm{d} a / \mathrm{d} N$, with respect to crack length. (c) Variation in fatigue crack growth rate with respect to the nominal stress intensity factor range. Open symbols represent the results before OL; solid symbols represent the results after OL.

\subsection{Synchrotron $X$-ray diffraction results}

\subsubsection{Stress maps and line profiles}

The crack-tip stress maps in the crack opening direction for the low and high $k_{I I}$ samples before, during and after overload at minimum and maximum load are shown in Fig. 8. The similarities and differences of stress variation between the two samples can be clearly observed and qualitatively compared from the 2D maps. However, the line profiles (see Fig. 9) taken along the crack plane for both samples extracted from the diffraction maps and line scans make it easier for quantitative analysis and comparison.

As is shown in Figs. 8 and 9, immediately after overload, the peak crack-tip stresses (in the crack opening direction) reached at $P_{\max }$ are reduced and the maximum compressive stress observed at $P_{\min }$ is more severe. This response is observed for both samples and is due to the compressive residual stress field introduced by increased plastic deformation around the crack tip associated with the overload cycle and is in accordance with previous observations for coarse grained materials [38]. 
For the high $k_{I I}$ sample, the maximum compressive stress reached at $P_{\min }$ is greatly increased ahead of the crack tip at the overload stage (see Fig. 8i(g) and Fig. 9ii(b)) due to the overload induced-plastic flow. It is also clear that, in common with the findings of Simpson on bainitic steel [38], compressive stresses are retained behind the crack tip as the crack propagates into the overload plastic zone (see Fig. 8i(j) and Fig. 9ii(d)). Finally, the magnitude of the compressive crack opening stress at $P_{\min }$ decreases as the crack propagates beyond the overload plastic zone (see Fig. 8i(k) and Fig. 9ii(e)).

For the low $k_{I I}$ sample, a more compressive stress at $P_{\min }$ after the application of overload is not observed in front of the crack tip. Instead, it is in the wake of the crack tip. This may be because the crack propagates a short distance during the overload cycle, which results in the release of certain amount of stress.

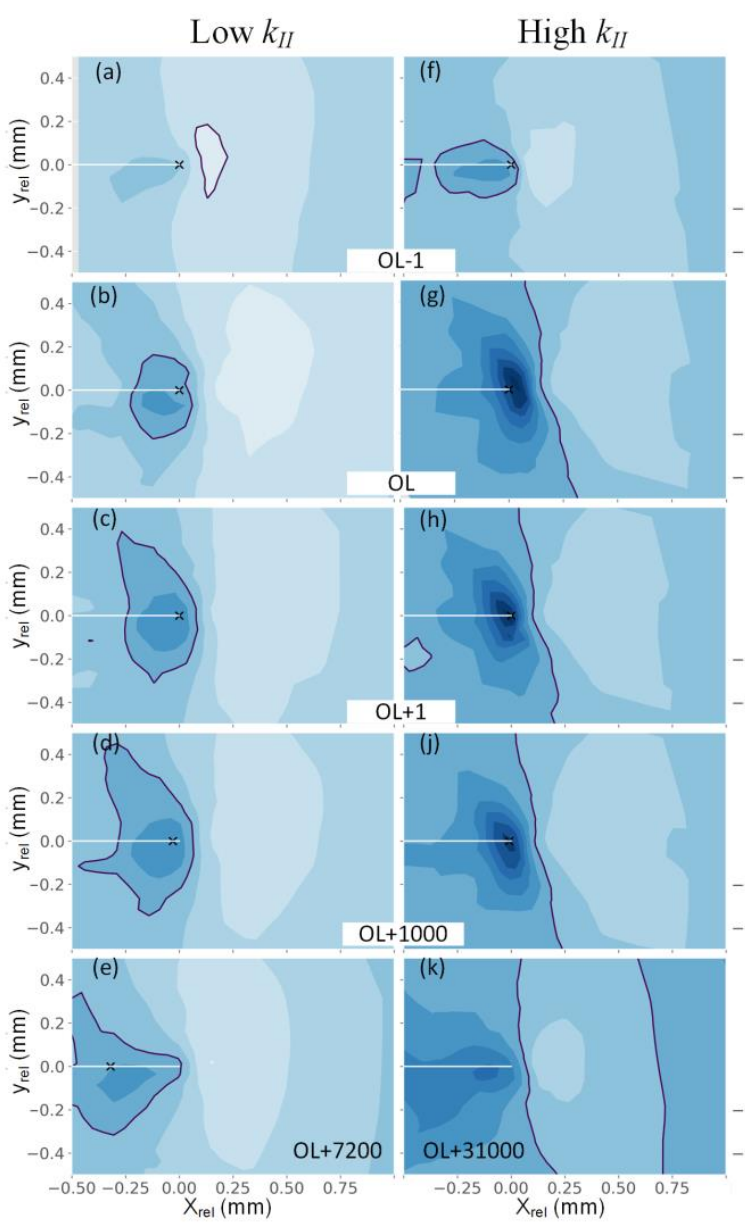

(i) At minimum load
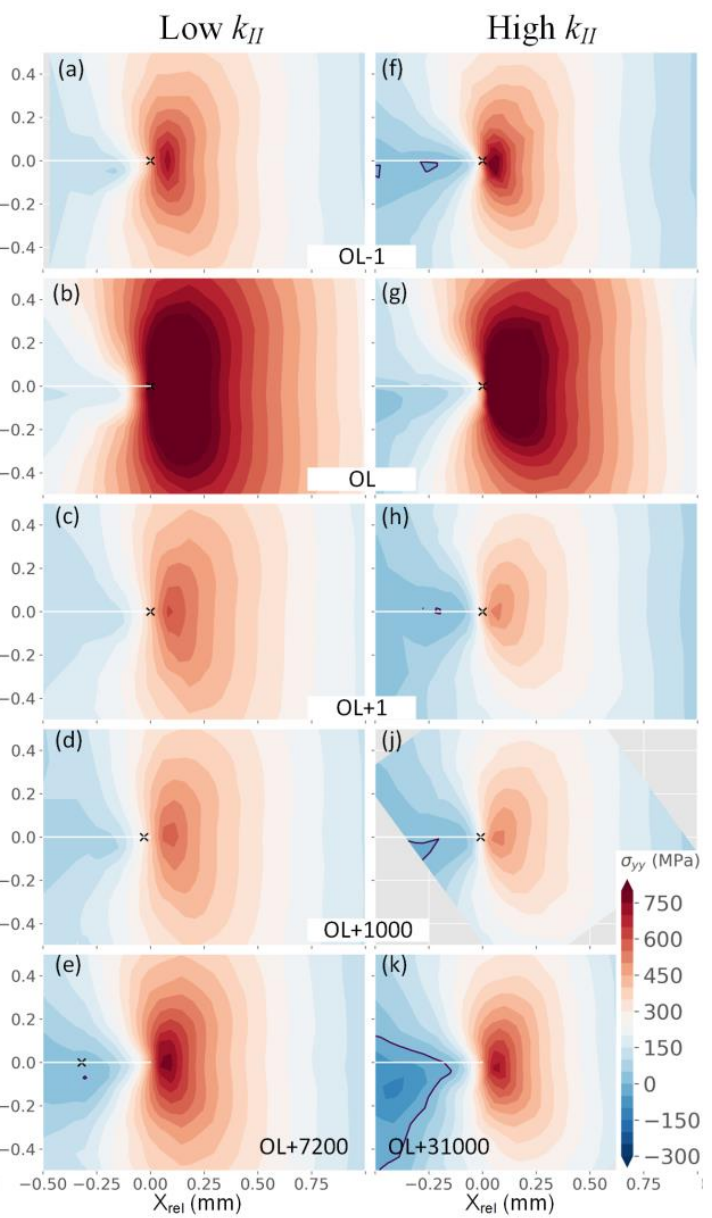

(ii) At maximum load

Fig. 8. Crack-tip stress fields for the crack opening direction $\sigma_{y y}$ after various numbers of fatigue cycles relative to the overload cycle for the low and high $k_{I I}$ samples at (i) minimum load and (ii) maximum load in the rotated relative coordinate system. The coordinates $\left(x_{r e l}\right.$ and $\left.y_{r e l}\right)$ describe the relative distance to the current crack-tip position. The white lines denote the current crack positions. The black cross symbols indicate the overload location. 
(i) Low $k_{I I}$
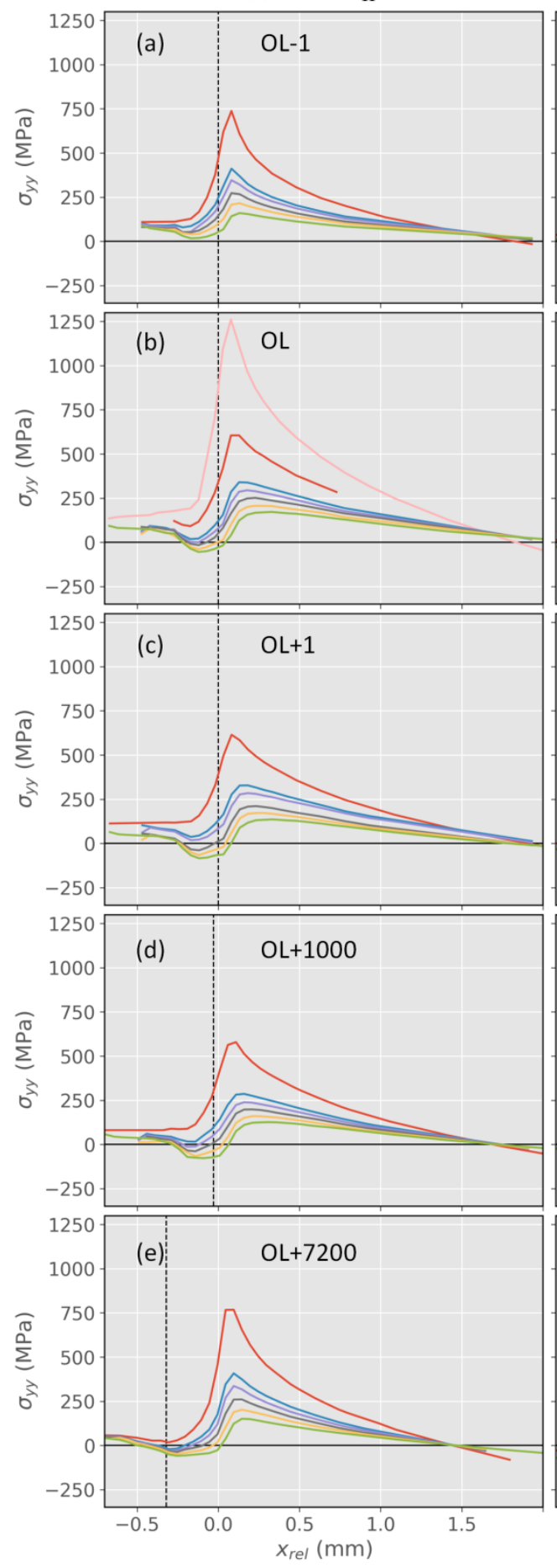

(ii) High $k_{I I}$
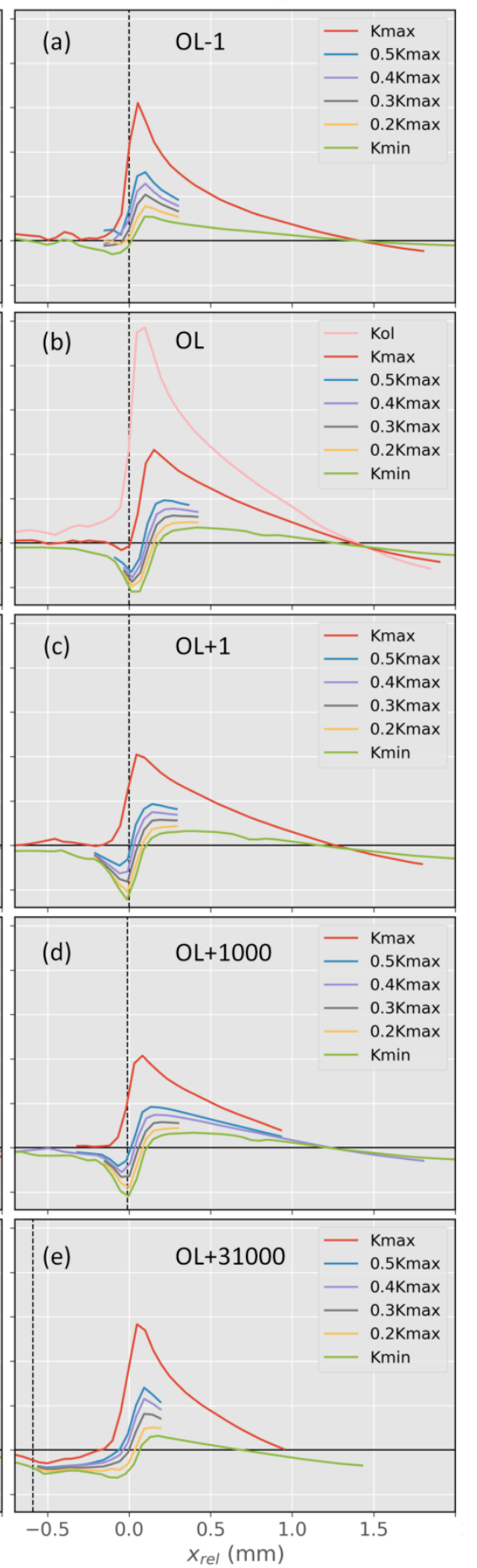

Fig. 9. Line profiles of the stresses in the crack opening direction along the crack faces for (i) the low $k_{I I}$ and (ii) the high $k_{I I}$ samples before, during and after overload in the rotated relative coordinate system. The horizontal coordinate $\left(x_{r e l}\right)$ describes the relative distance to the current crack-tip position. The black dashed lines indicate the overload location.

It is noteworthy that the compressive stresses are largest at $P_{\min }$ immediately after overload for both samples. The maximum compressive stress at $P_{\min }$ remains essentially constant even 
as the crack starts to grow through it (stages OL+1 and OL+1000) as observed in Figs. 8 and 9. This is due to the absence of large scale plasticity under the high cycle fatigue conditions during the subsequent cycling such that the compressive misfit created by the plastic stretch at overload can be transferred across the touching crack faces at $P_{\min }$. This has been observed by energy dispersive $\mathrm{X}$-ray diffraction as a crack passes through a compressive stress field produced by overload fatigue as well as laser peening in [39].

It is evident from Figs. 8 and 9 that the increase in the compressive stresses at $P_{\min }$ and the reduction of the peak stresses at $P_{\max }$ after overload are more significant for the high $k_{I I}$ orientation than for the low $k_{I I}$ orientation. This is due to the larger mode II component and crack roughness which combine to give higher crack closure and will be discussed in detail in section 4.2.

\subsubsection{The effective stress intensity factor}

The effective mixed mode stress intensity factor $k_{\max }$ at $P_{\max }$ was determined directly by fitting the synchrotron X-ray diffraction strain maps as explained in section 2.3, while the stress intensity factor range, $\Delta k=k_{\max }-k_{\min }$, was obtained by subtracting the two strain fields at $P_{\max }$ and $P_{\min }$ and then fitting the strain field. The results at the various stages of fatigue growth are shown in Fig. 10 for both specimens. The effective results are broadly consistent with the nominal ones in terms of the cycles before overload and well after overload except the $\Delta k$ results in the low $k_{I I}$ orientation. It is noticeable that in the low $k_{I I}$ case the effective $\Delta k$ values are depressed across all the measurements relative to the nominal possibly because the effective values of $k_{\min }$ at $P_{\min }$ are larger than expected. In spite of this, it is clear that $k_{\max }$ and $\Delta k$ for both specimens are slightly below those nominally applied immediately after overload. This difference increases as the crack grows a short distance before returning towards those representative of the baseline fatigue state. This is in agreement with the results of the stress maps and line profiles in Figs. 8 and 9 and the FCG results in Fig. 7. The decrease in $k_{\max }$ reflects the effect of the residual stress and the reduction of $\Delta k$ reflects crack closure. 

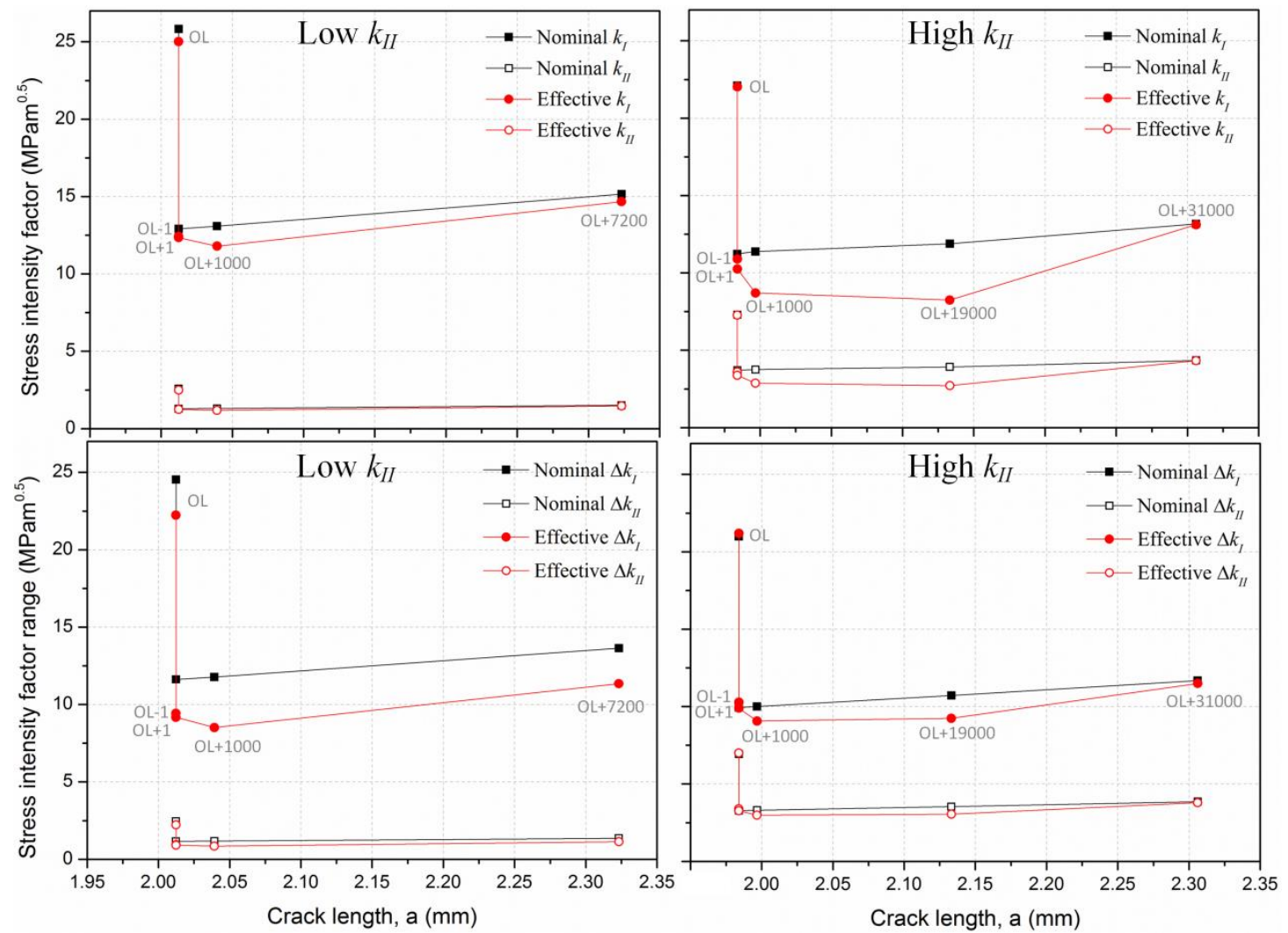

Fig. 10. Comparison between the nominal and the effective (inferred from the crack-tip strain field) $k_{\max }$ and $\Delta k$ before, during and after overload for the low and high $k_{I I}$ orientations.

\subsection{Digital image correlation results}

The strain and stress field measured by synchrotron X-ray diffraction under plane strain shows the combined effects of residual stress and crack closure on the overload retardation. Digital image correlation was applied to measure the surface behaviour under plane stress by evaluating the crack opening displacement and SIF range from the displacement field. In addition, we were able to study more fatigue stages due to the faster acquisition time.

\subsubsection{Crack opening displacement}

The crack opening displacement results are extracted from the crack-tip displacement field for both samples, as shown in Fig. 11. For the low $k_{I I}$ sample, there is no evidence of closure until the crack has grown $\sim 40 \mu \mathrm{m}$ ahead of the OL position (i.e. after 1000 cycles). This is consistent with the fact that the $\triangle \mathrm{COD}$ results suggest that the crack surfaces contact over a length of around $38 \mu \mathrm{m}$. In addition, when the crack has grown $\sim 90 \mu \mathrm{m}$ beyond the OL position $(\mathrm{OL}+3300)$, the $\triangle \mathrm{COD}$ results indicate that the crack surfaces contact one another over a distance of $76 \mu \mathrm{m}$ behind the current crack tip. At this stage crack closure is at its most significant. As the crack grows further the FCG rate starts to recover such that after 7200 
cycles no closure is evident in the $\triangle \mathrm{COD}$ results.

(i) Low $k_{I I}$
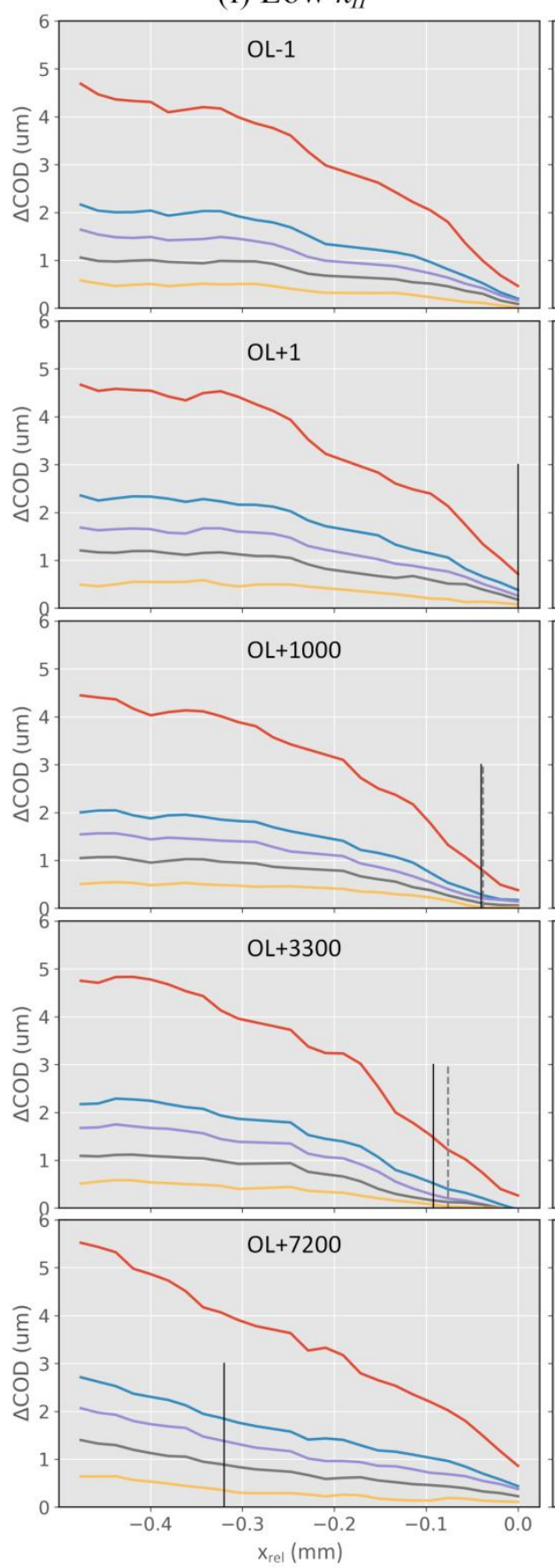

(ii) High $k_{I I}$
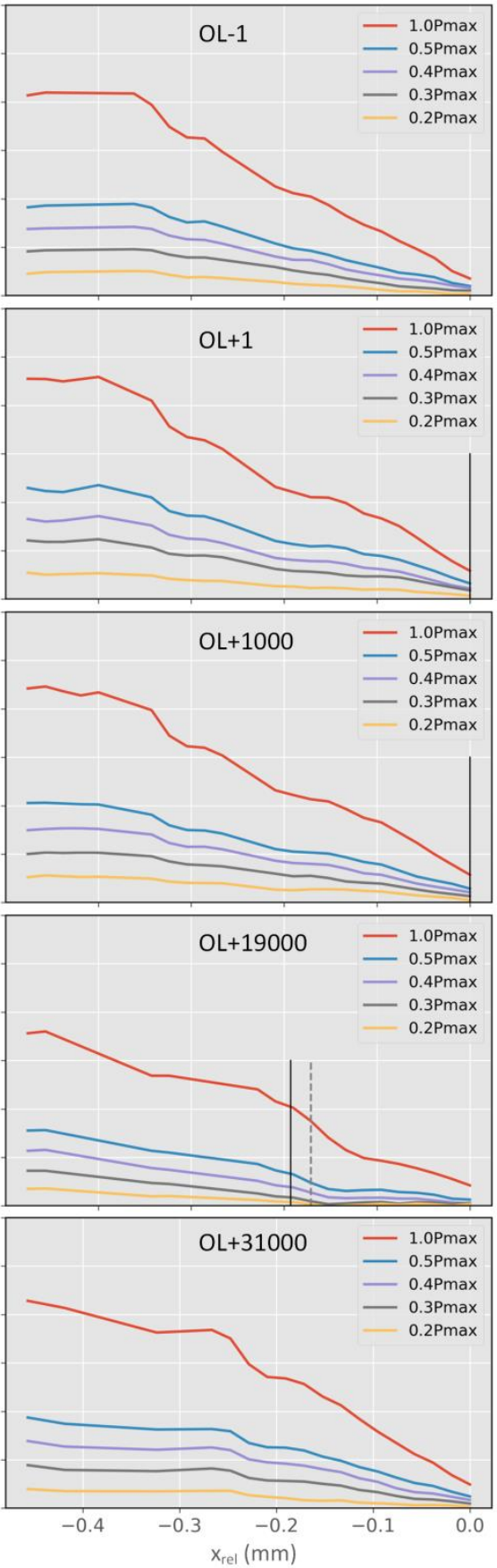

Fig. 11. Crack opening displacement as function of distance from the crack tip at various loading levels of each fatigue stage for the (i) low $k_{I I}$ and (ii) high $k_{I I}$ orientations in the rotated relative coordinate system. The horizontal coordinate $\left(x_{\text {rel }}\right)$ describes the relative distance to the current crack-tip position. The gray dashed lines indicate the crack face contact length. The black solid lines show the overload positions.

For the high $k_{I I}$ orientation, the same trend is observed in that crack closure is absent 
immediately after overload until the crack has grown to a certain distance into the overload plastic zone. However, the closure effect after 19000 cycles is much more significant than at any stage for the low $k_{I I}$ sample. From the $\Delta$ COD results, the crack faces contact length is approximately $170 \mu \mathrm{m}$ after 19000 cycles, at which point the crack has actually grown around $190 \mu \mathrm{m}$ past the overload position.

It is also observed in Fig. 11 that the $\Delta \mathrm{COD}$ values at $P_{\max }$ for the high $k_{I I}$ sample after 19000 cycles are evidently smaller than that of the other stages. The smaller $\Delta \mathrm{COD}$ at $P_{\max }$ and the larger crack surface contact length at $P_{\min }$ are consistent with the fact that the overload retardation effect is more significant when there is a large $k_{I I}$ component compared to low $k_{I I}$.

It should be also noted that the DIC results are suggestive of continuous crack closure although it is not possible to tell from the DIC results whether load is transferred across the whole length of crack face contact.

\subsubsection{Stress intensity factor range}

The variation in $\Delta k$ inferred from the surface displacement maps before, during and after OL are shown in Fig. 12. The effective $\Delta k$ very slightly declines immediately after OL before a more significant drop as the crack was grown into the overload plastic zone. These results are broadly in agreement with those obtained from the synchrotron data (see Fig. 10) but show a clearer trend in that the $\Delta k$ values for high $k_{I I}$ drop more significantly than for low $k_{I I}$ after overload. This confirms the SXRD results that the closure level at high $k_{I I}$ is greater than for low $k_{I I}$.

The application of SXRD and DIC makes it possible to evaluate the effective values of $k_{\max }$ and $\Delta k$ and thus the effective crack driving force as a function of crack length relative to the OL position. Moreover, $R$ ratio (minimum load / maximum load) is believed to have a significant effect on the fatigue behaviours [40]. In our following paper [41], the overload fatigue behaviours at $R=0.1$ and $R=0.5$ are compared using $(\Delta k)^{\gamma}\left(k_{\max }\right)^{1-\gamma}$ (Walker's model [42]) as the crack driving force, $\Delta k_{e q}$. The FCG rates are then correlated with the effective $\Delta k_{e q}$ considering both the effects of residual stress and crack closure and the mean stress effect. 


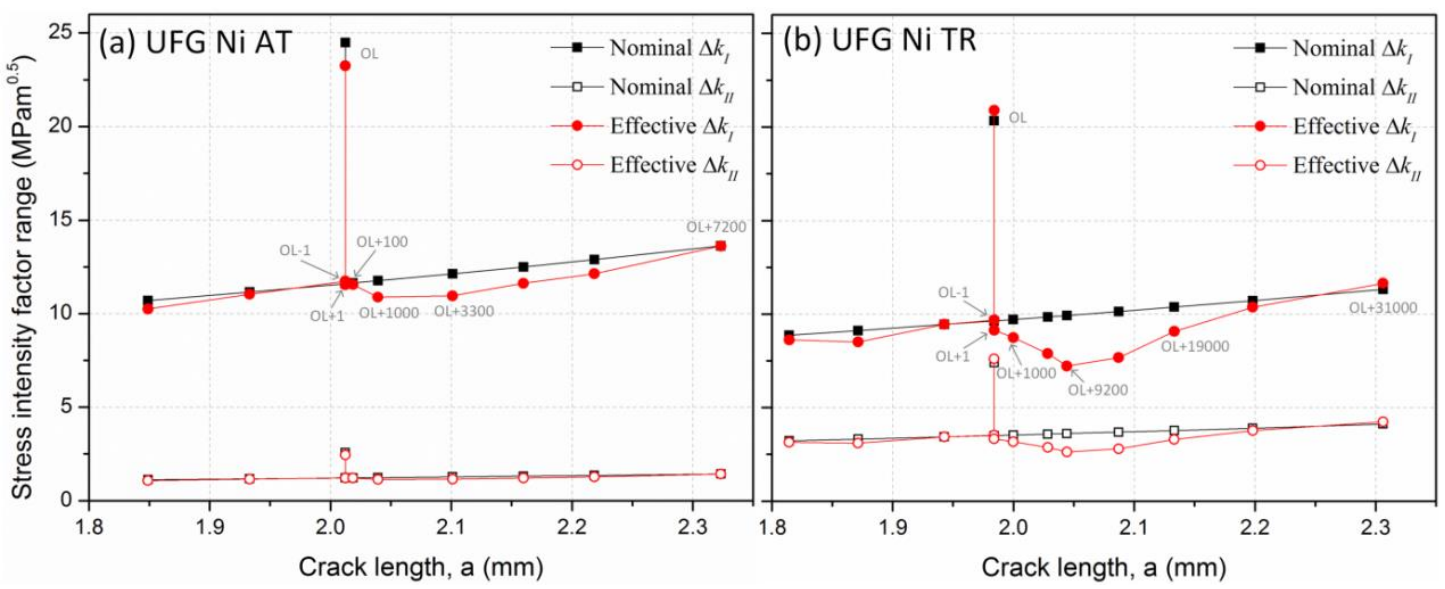

Fig. 12. Comparison between the nominal and effective (inferred from the crack-tip surface displacement field) $\Delta k$ before, during and after overload for UFG Ni in the low and high $k_{I I}$ orientations.

\subsection{Fracture surface morphology}

The crack morphologies are shown in Fig. 13. Though the cracks are not perpendicular to the loading direction, because they have been deflected by the elongated grains, they are very smooth. It is evident that the material was significantly stretched and the cracks were greatly opened when the overload was applied preventing crack face contact of the faces behind the overload position.

The fracture surfaces for the low and high $k_{I I}$ samples are shown in Figs. 14 and 15 respectively. The overload locations are delineated by the boundaries dividing the fractographs into two parts in Figs. 14a and 15a. Here crack face contact is evidenced by the dark and comparatively flat regions, which are more clearly depicted at higher magnification. It can also be observed in low magnification that the high $k_{I I}$ sample not only has a significantly rougher fracture surface, but experienced a higher level of crack face contact. For both cases, the morphology of the regions beyond the overload where the FCG rates have returned to the baseline state is similar to that before the overload.

The high magnification images taken in the regions before the overload (in Figs. 14c and $15 \mathrm{c})$ indicate the fracture surface for both samples is very smooth. With reference to the EBSD results in Fig. 6, the crack surface morphologies are consistent with intergranular crack growth. The closure regions comprising a cluster of grains on both surfaces of the crack contacting each other are also clearly shown at high magnification (Figs. 14d and 15d). Regularly aligned features are observed to be perpendicular to the crack propagation direction at the relatively flat closure locations for both samples. These lines have a larger spacing than would be consistent with traditional mode I fatigue striations and suggest repeated crack face contact aided by the local mode II loading. 

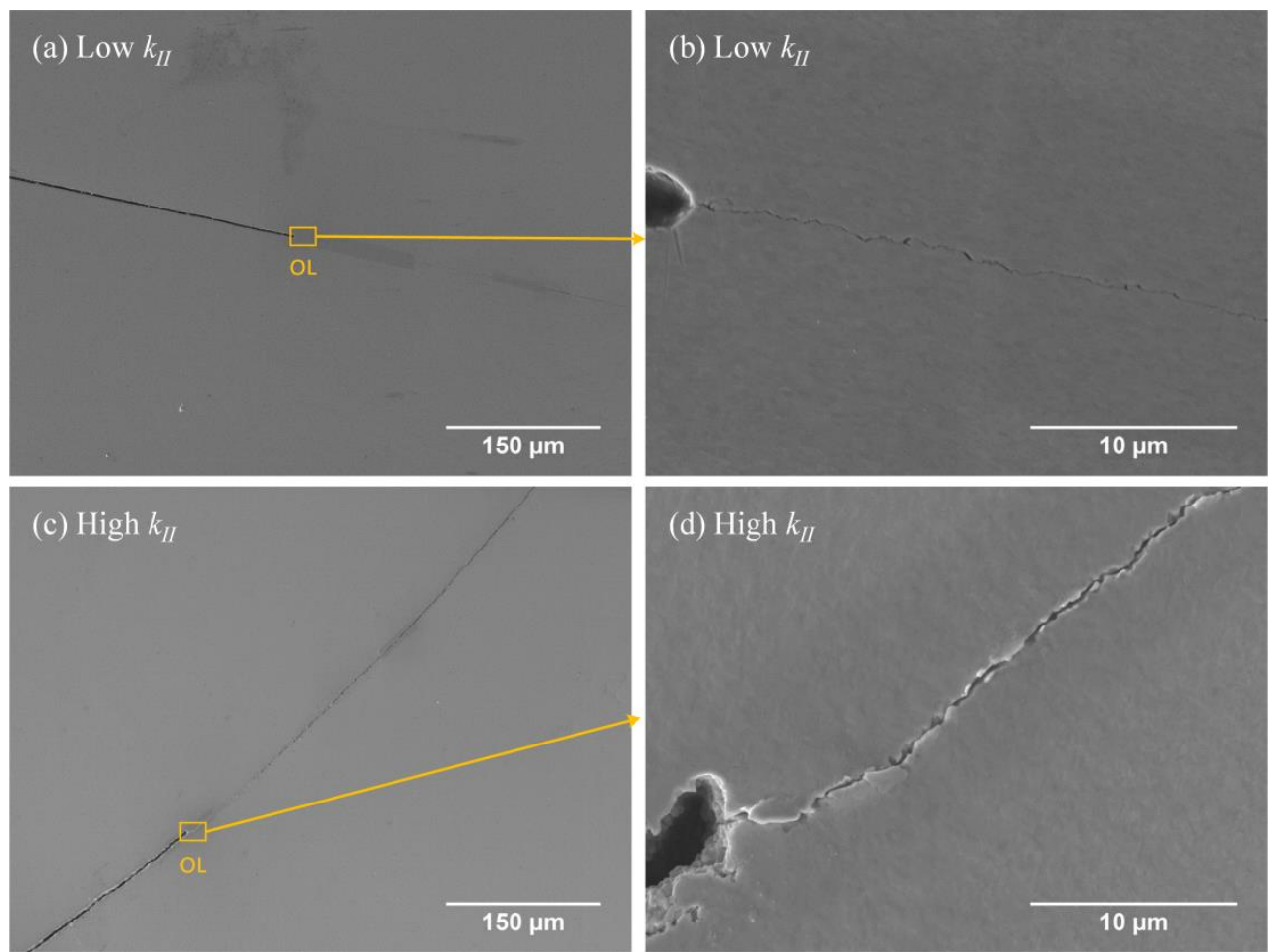

Fig. 13. Low (LHS) and high (RHS) magnification SEM images of the cracks for UFG Ni in the low and high $k_{I I}$ orientations. The crack propagation direction is from left to right. The loading direction is vertical.

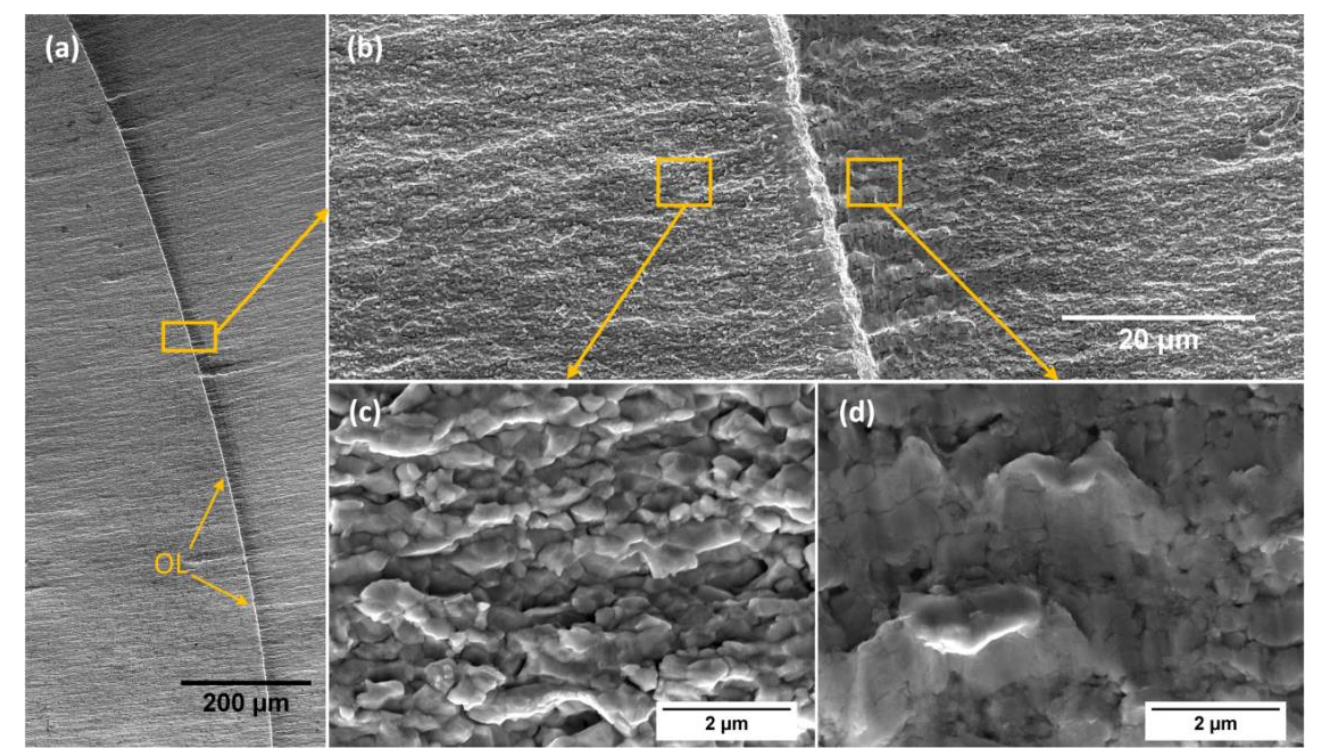

Fig. 14. Fractographs from the experiment for the low $k_{I I}$ case. (a) Low magnification image of full crack face. The boundary dividing the fractograph into two parts is the overload position. (b) Higher magnification of mid-thickness region. The dark and flat region to the right of the overload indicates the points of crack face contact. (c) High magnification before the overload showing no evidence of crack closure. (d) High magnification immediately after the overload showing characteristic crack face contact scars. The crack propagation direction is from the left to right. 


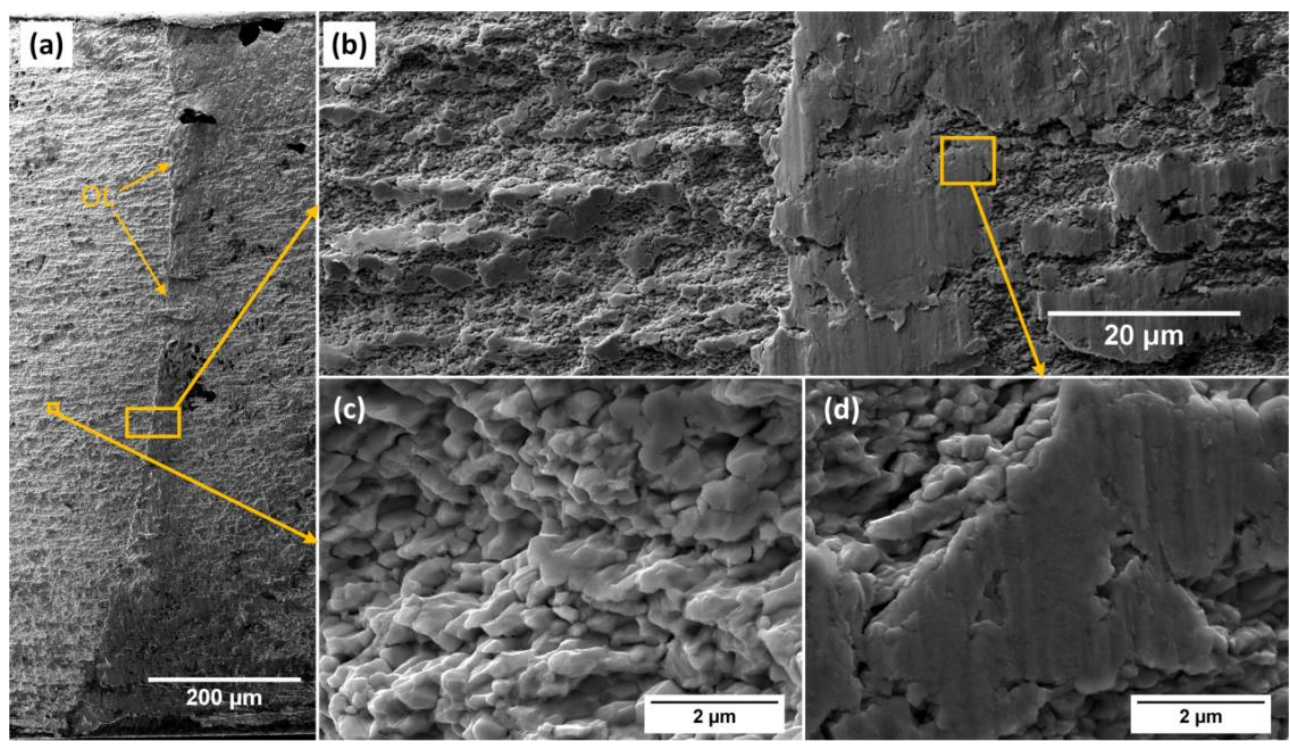

Fig. 15. Fractographs from the experiment for high $k_{I I}$ case. (a) Low magnification image of full crack face. The boundary dividing the fractograph into two parts is the overload position. (b) Higher magnification from mid-thickness region. The dark and flat region to the right of the overload indicates the points of crack face contact. (c) High magnification before the overload showing no evidence of crack closure. (d) High magnification immediately after the overload showing characteristic crack face contact scars. The crack propagation direction is from the left to right.

\subsection{Roughness results}

As described above, the crack paths are deflected for both samples, which reduces the local stress intensity and enhances the local mode II loading around the crack tip. Crack surface contact is also observed and becomes significant after the overload. These factors suggest surface roughness may be an important parameter.

Plasticity-induced crack closure should be similar for both samples since a similar stress intensity was applied at the OL. However, crack surface contact is more significant for the high $k_{I I}$ sample than the low one. Different roughness levels and mode II components may explain this.

In order to quantify any difference in roughness between the two samples, small patches (dashed squares in $100 \times 100 \mu \mathrm{m}^{2}$ as shown in Fig. 16a were examined by a confocal laser scanner, NanoFocus $\mu$ Scan Custom, on both sides of the OL position. The results are shown in Table 3. The arithmetical mean roughness, $R_{\mathrm{a}}$, for the high $k_{I I}$ sample is much larger than that for the low $k_{I I}$ sample. In addition, a larger subset window (solid square in $200 \times 200 \mu \mathrm{m}^{2}$ as shown in Fig. 16a was utilized to extract 3D roughness profiles at the OL positions to give a clear comparison between the samples. The 3D profiles for the low and high $k_{I I}$ samples are shown in Fig. 16b and Fig. 16c, respectively. It can be seen that the fracture surface for the 
high $k_{I I}$ sample is evidently rougher than that for the low $k_{I I}$ one. This contributes to more significant crack surface contact for the high $k_{I I}$ case.

Table 3 Roughness results $\left(R_{\mathrm{a}}\right.$ in $\left.\mu \mathrm{m}\right)$ before and after overload for UFG nickel in the low and high $k_{I I}$ cases measured by a confocal laser scanner.

\begin{tabular}{|l|c|c|c|c|c|c|c|c|c|c|}
\hline Sample & \multicolumn{5}{|c|}{ Low $k_{I I}$} & \multicolumn{5}{c|}{ High $k_{I I}$} \\
\hline Position & 1 & 2 & 3 & 4 & 5 & 1 & 2 & 3 & 4 & 5 \\
\hline Before OL & 0.54 & 0.41 & 0.44 & 0.46 & 0.66 & 0.88 & 0.79 & 0.88 & 1.08 & 1.48 \\
\hline After OL & 0.44 & 0.45 & 0.44 & 0.47 & 0.51 & 1.23 & 0.92 & 1.02 & 1.60 & 1.78 \\
\hline
\end{tabular}
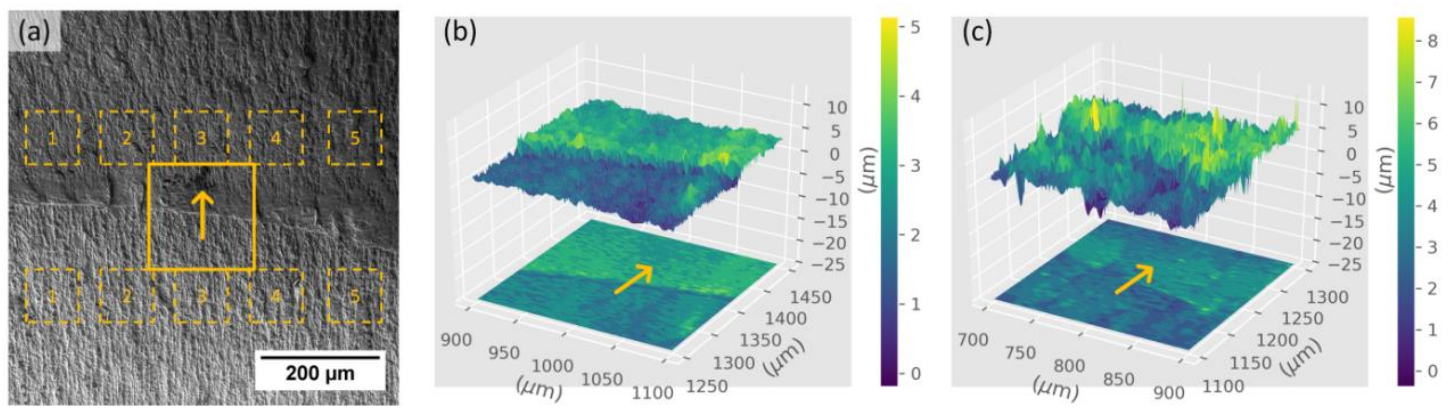

Fig. 16. (a) Schematic of the positions for the roughness measurement on the fractograph. The boundary dividing the fractograph into two parts is the overload position. The solid square in the center of the fractograph containing the overload regions describes the position for extracting 3D roughness profiles for both samples as shown in b) and c). The arrows describe the crack propagation direction. (b) 3D roughness profiles for low $k_{I I}$. (c) 3D roughness profiles for high $k_{I I}$.

\section{Discussion}

\subsection{Delayed crack growth retardation}

It can be seen from Fig. 7 that in both cases the FCG rate immediately after overload is similar to the baseline state. Significant compressive residual stresses arise from the plastic flow introduced by the overload as shown in Figs. 8 and 9 as well as some degree of crack blunting (see Fig. 13). This would appear to be because the crack faces are pulled apart by the overload stretch, which prevents the occurrence of crack face contact behind the crack tip. This is evidenced by the SXRD (see Fig. 10) and DIC (see Fig. 12) and means that, while the compressive stress decreases the mean stress, the stress intensity factor range does not reduce immediately after overload. The argument is also supported by the crack opening displacement results as shown in Fig. 11 where no face contact is observed behind the overload location. It seems likely that the retardation effects of residual stress and crack-tip blunting immediately after overload are offset by the reduction in plasticity induced crack 
closure brought about by the crack opening.

As the crack propagates into the overload plastic zone, the FCG rate starts to decrease (as shown in Fig. 7). Crack face contact is observed in the region between the current crack-tip position and the overload position (see Figs. 14 and 15). This is because the crack opening displacement is significantly reduced by the overload through the combination of the crack growing through a compressive residual stress and the plastic stretch which means that significant compressive stresses are transferred across the faces holding the crack open at $P_{\min }$ thereby reducing the effective stress intensity range. Eventually as the crack grows out of the overload plastic zone these effects lessen and the FCG rate returns towards the baseline value.

\subsection{The effect of grain orientation}

The stress fields in the crack opening direction around the crack tip at overload shown in Fig. 9(ib and iib) are similar for both samples. The $\triangle \mathrm{COD}$ at the OL position as shown in Fig. 13 is also similar for the two samples, which indicates the same stress intensity factor range was applied. However, the residual stress (see Figs. 8 and 9) and crack face contact (see Fig. 15) are observed to be more significant for the high $k_{I I}$ orientation than for low $k_{I I}$ sample.

A clear demarcation can be observed on the fracture surfaces in Fig. 14 (a, c) at the overload location. However, the boundaries for the two samples are different. A bright and narrow band is observed in between the two regions for low $k_{I I}$ which is absent for high $k_{I I}$ which may indicate that the crack propagated a short distance when the overload was applied. This ductile tearing due to the application of overload is also observed in a titanium alloy in [43]. As is discussed in section 3.5, intergranular crack growth dominates the whole fatigue process. For the low $k_{I I}$ sample, the nominal SIF drives crack growth is along the grain elongation direction, which may result in a significant extension of the crack on overload. The overload-induced transient FCG is expected to release some of the residual stress that should have accumulated around the crack tip during unloading from $P_{O L}$ to $P_{\min }$, which would therefore reduce the observed level of compressive residual stress immediately after overload for the low $k_{I I}$ sample.

As the crack propagates away from the overload position, the residual stress and crack face contact for the low $k_{I I}$ sample is not as significant as for the high $k_{I I}$ case. Crack defection and surface roughness play a more important role after overload when crack closure is prominent. Crack deflection not only increases the effective crack length but also the local mode II load as illustrated in Eq. 7, which promotes the mismatch between the crack faces and provides more opportunities for the faces to contact one another. That means a higher deflection angle as seen for the high $k_{I I}$ sample is beneficial to the enhancement of roughness-induced crack 
closure and probably explains why greater retardation is observed.

\subsection{Further observations}

The crack morphology measured by SEM after the fatigue overload experiment for both samples is shown in Fig. 17. The crack opening is usually very small at the minimum load (especially after overload when closure is present) and crack face contact usually takes place within the plastic zone. This makes it difficult to accurately measure the contact of the crack flanks over several or several tens of micrometres by DIC. It is also difficult to resolve continuous and discontinuous crack closure either from the DIC images or the displacement field because of the relatively low resolution in term of the difference within micrometre.

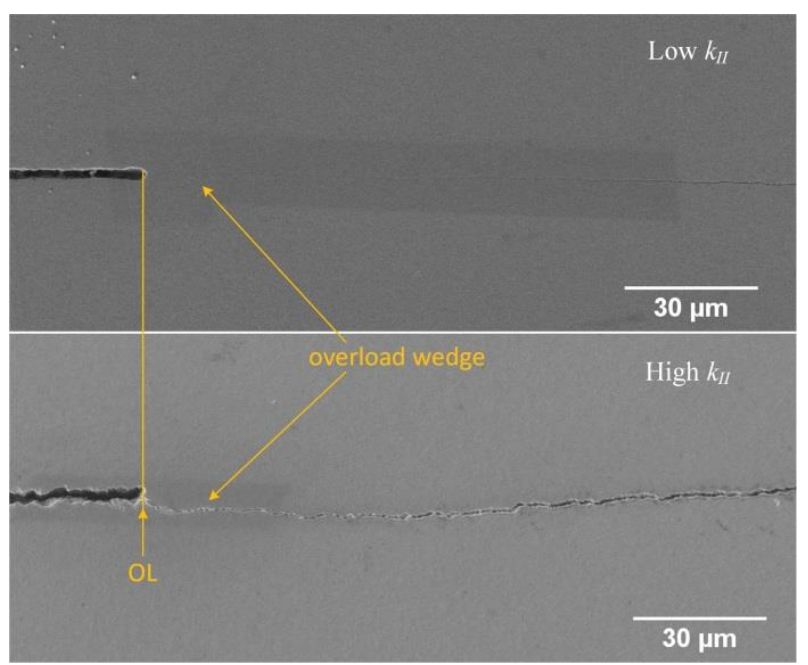

Fig. 17. Post mortem crack morphology for the low and high $k_{I I}$ samples showing the crack closure within a short distance immediately after overload acts as a wedge that holds the rest of the crack open. The cracks have grown around $600 \mu \mathrm{m}$ past OL for both samples.

When considering the stress maps, it should be remembered that the X-ray gauge volume has lateral dimensions of $50 \mu \mathrm{m} \times 50 \mu \mathrm{m}$ and samples the crack-tip stress field over the full through-thickness of the sample. Given that the crack is not perfectly straight, this also smears out the recorded crack-tip profiles. The measured strains are therefore a convolution of strains at multiple locations. In Fig. 18 deconvoluted results are presented for the high $k_{I I}$ sample; a Gaussian response function has been applied to the measured SXRD results with a window width equal to $200 \mu \mathrm{m}(\mathrm{FWHM}=100 \mu \mathrm{m})$. This window width is consistent with the sum of the length of the curved crack front $(\sim 150 \mu \mathrm{m}$ in Fig. 15) and the gauge length $(50 \mu \mathrm{m})$. Thus for the low $k_{I I}$ sample, a Gaussian response function with window width equal to $350 \mu \mathrm{m}$ (sum of the length of the curved crack front, $300 \mu \mathrm{m}$ in Fig. 14, and the gauge length, $50 \mu \mathrm{m}$ ) was used. The deconvoluted result indicated by the solid curves in Fig. 18 shows the 
underlying stress distribution around the crack tip and highlights that the diffraction measured result underestimates both the peak stress at $P_{O L}$ and the compressive stress at $P_{\min }$. It is worth noting that both the measured and deconvolved stress at the crack tip are larger than the yield stress. This is because the (311) peak shift (measured in this work) is weakly influenced by the development of intergranular strains/stresses and, as such, stress and lattice strain are linearly related (and can be assessed) beyond yield. Furthermore, the measured stress has a gentle slope at the crack tip compared with the sharp vertical slope at the crack tip for the underlying stress distribution, which is due to the noted smearing effect. However, the smearing effect is less important in the elastic fields beyond the crack tips which is due to the shallower strain gradient and explains the good fit to the data in Figure 4b. If a re-convolution is then performed on the underlying, deconvolved profiles using the same response function, the resultant profile should be very similar to the measured one. This is confirmed in Fig. 18. Knowing the underlying stress distribution, the underlying crack-tip position can then be found with a higher degree of certainty.

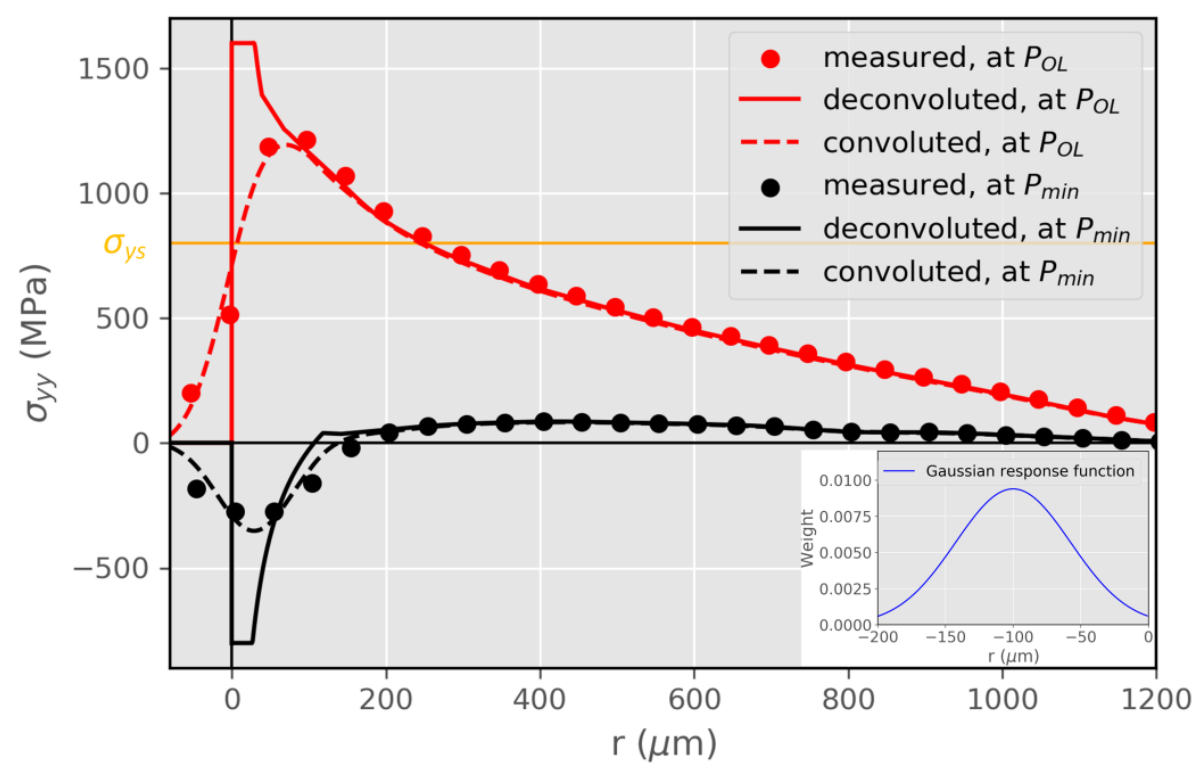

Fig. 18. The deconvolution and convolution for the high $k_{I I}$ sample at the OL cycle using a Gaussian response function with FWHM of $100 \mu \mathrm{m}$. The stress profiles measured by synchrotron X-ray diffraction are first deconvoluted to acquire the underlying crack-tip stress distribution as indicated by the solid curves. Then these values are re-convoluted to validate the method and the resultant stress profiles closely match the measured results.

\section{Conclusion}

Fatigue cycling under constant amplitude loading at a load ratio of $R=0.1$ was conducted on two compact tension samples of ultrafine grained $\mathrm{Ni}$, one oriented in the AT and the other the TR orientation. In the former case the grains were elongated essentially along the 
expected crack growth plane while for the TR sample the grains are elongated essentially perpendicular to the intended crack plane. In both cases the cracks diverted significantly to align with the grain to give low and high $k_{I I}$ components respectively. A $100 \%$ overload $\left(P_{O L}\right.$ $=2 P_{\max }$ ) was applied generating an overload plastic zone size around $330 \mu \mathrm{m}$ (as estimated by Irwin's model).

SXRD and DIC were used to study the effect of the overload as a function of crack growth past it. The spatial resolution for SXRD and DIC are $50 \mu \mathrm{m}$ and $6.4 \mu \mathrm{m}$ respectively, although in the former case the averaging effect through thickness was deduced to smear the crack-tip stress profiles by around FWHM of $175 \mu \mathrm{m}$ for the low $k_{I I}$ sample and $100 \mu \mathrm{m}$ for the high $k_{I I}$ sample. The variation in crack opening stress and stress intensity factor (taken as a through-thickness average) were evaluated by SXRD and the changes in crack length, crack opening displacement and stress intensity factor range at the surface were determined by DIC. Post mortem fractography and surface roughness have been used to help explain the mechanisms for the samples with different elongated microstructure.

It can be concluded that:

(1) The elongated grain alignment has a significant effect on the baseline FCG deflecting the crack growth direction orientation (by $12^{\circ}$ and $50^{\circ}$ for the AT and TR orientations respectively to give different levels of mode mixity despite the crack path running along the grain orientation direction in both cases). The FCG rate for the high $k_{I I}$ sample is approximately $2.4 \times$ slower than for the low $k_{I I}$ sample for the same $\Delta k$ considering the local mixed mode loading conditions.

(2) No significant drop in FCG rate was observed immediately after overload in either sample. It is believed that the significant permanent COD arising from the OL prevents crack face contact behind the overload position.

(3) Significant compressive residual stresses were generated in the crack-tip zone in both cases.

(4) Upon crack growth from the overload, the FCG rate slowed significantly for both samples as the crack propagated into the overload plastic zone. The combined effect of residual stress and plasticity-induced crack closure gives rise to significant crack closure and compressive forces transferred across the faces at $P_{\min }$. This maintains a tensile stress at the crack tip and reduces $\Delta k^{\text {eff }}$. The mode II element resulting from crack deflection promotes the effect of roughness-induced crack closure, which also contributes to the retardation in FCG.

(5) The residual stress and crack closure levels are more significant for high $k_{I I}$ than for low $k_{I I}$. The larger mode II and the rougher fractured surfaces associated with the TR 
sample are responsible for the difference between the two samples. However, the overload retardation length is very similar for both samples.

(6) Compared with conventional (coarse) grain $\mathrm{Ni}$, the ultrafine grained $\mathrm{Ni}$ is less retarded by overload because of its relatively flatter crack path and higher yield stress and thus less plasticity and residual stress under the same loading conditions [44].

\section{Acknowledgement}

We acknowledge Diamond Light Source for time at beamline I12:JEEP under proposal EE16647. We are grateful for the support of the beamline staff member Stefan Michalik. WZ is grateful for the financial support from the China Scholarship Council (CSC) and the helpful discussions with Pablo Lopez-Crespo. PJW acknowledges support from the European Research Council grant No. 695638 CORREL-CT. We are very grateful for the comments from the referees.

\section{References}

[1] R.Z. Valiev, R.K. Islamgaliev, I. V. Alexandrov, Bulk nanostructured materials from severe plastic deformation, Prog. Mater. Sci. 45 (2000) 103-189. doi:10.1016/S0079-6425(99)00007-9.

[2] N.A. Fleck, Fatigue crack growth due to periodic underloads and overloads, Acta Metall. 33 (1985) 1339-1354. doi:10.1016/0001-6160(85)90244-5.

[3] S. Suresh, Fatigue of materials, Cambridge Univ. Press. (1991).

[4] E. Wolf, Fatigue crack closure under cyclic tension, Eng. Fract. Mech. 2 (1970) 37-45. doi:10.1016/0013-7944(70)90028-7.

[5] W. Elber, The Significance of Fatigue Crack Closure, in: Damage Toler. Aircr. Struct., ASTM International, West Conshohocken, PA, 1971: pp. 230-242. doi:10.1520/STP26680S.

[6] N. Louat, K. Sadananda, M. Duesbery, A.K. Vasudevan, A theoretical evaluation of crack closure, Metall. Trans. A. 24 (1993) 2225-2232. doi:10.1007/BF02648597.

[7] K. SADANANDA, Analysis of overload effects and related phenomena, Int. J. Fatigue. 21 (1999) 233-246. doi:10.1016/S0142-1123(99)00094-8.

[8] V.W. Trebules, R. Roberts, R.W. Hertzberg, Effect of Multiple Overloads on Fatigue Crack Propagation in 2024-T3 Aluminum Alloy, in: Prog. Flaw Growth Fract. Toughness Test., ASTM International, 100 Barr Harbor Drive, PO Box C700, West Conshohocken, PA 19428-2959, 1973: pp. 115-146. doi:10.1520/STP49719S.

[9] M. Beghini, L. Bertini, Fatigue crack propagation through residual stress fields with closure phenomena, Eng. Fract. Mech. 36 (1990) 379-387. doi:10.1016/0013-7944(90)90285-O.

[10] F. Yusof, P. Lopez-Crespo, P.J. Withers, Effect of overload on crack closure in thick and thin specimens via digital image correlation, Int. J. Fatigue. 56 (2013) 17-24. doi:10.1016/j.ijfatigue.2013.07.002. 
[11] L.P. Borrego, J.M. Ferreira, J.M. Pinho da Cruz, J.M. Costa, Evaluation of overload effects on fatigue crack growth and closure, Eng. Fract. Mech. 70 (2003) 1379-1397. doi:10.1016/S0013-7944(02)00119-4.

[12] P. Lopez-Crespo, A. Steuwer, T. Buslaps, Y.H. Tai, A. Lopez-Moreno, J.R. Yates, P.J. Withers, Measuring overload effects during fatigue crack growth in bainitic steel by synchrotron X-ray diffraction, Int. J. Fatigue. 71 (2015) 11-16. doi:10.1016/j.ijfatigue.2014.03.015.

[13] A. Steuwer, M. Rahman, A. Shterenlikht, M.E. Fitzpatrick, L. Edwards, P.J. Withers, The evolution of crack-tip stresses during a fatigue overload event, Acta Mater. 58 (2010) 4039-4052. doi:10.1016/j.actamat.2010.03.013.

[14] N.A. Fleck, Finite element analysis of plasticity-induced crack closure under plane strain conditions, Eng. Fract. Mech. 25 (1986) 441-449. doi:10.1016/0013-7944(86)90258-4.

[15] H. Alizadeh, D.A. Hills, P.F.P. De Matos, D. Nowell, M.J. Pavier, R.J. Paynter, D.J. Smith, S. Simandjuntak, A comparison of two and three-dimensional analyses of fatigue crack closure, Int. J. Fatigue. 29 (2007) 222-231. doi:10.1016/j.ijfatigue.2006.03.014.

[16] P.J. Withers, Fracture mechanics by three-dimensional crack-tip synchrotron X-ray microscopy, Philos. Trans. R. Soc. A Math. Phys. Eng. Sci. 373 (2015). doi:10.1098/rsta.2013.0157.

[17] P.J. Withers, Residual stress and its role in failure, Reports Prog. Phys. 70 (2007) 2211-2264. doi:10.1088/0034-4885/70/12/R04.

[18] H. Nowack, K. Trautmann, K. Schulte, G. Lüutjering, Sequence Effects on Fatigue Crack Propagation; Mechanical and Microstructural Contributions, Fract. Mech. (2009) 36-36-18. doi:10.1520/stp34905s.

[19] R. Horstman, K. Peters, C. Enright, R. Meltzer, M. Bruce Vieth, M. Halliday, C. Beevers, Some Aspects of Fatigue Crack Closure in Two Contrasting Titanium Alloys, J. Test. Eval. 9 (2009) 195. doi:10.1520/jte11227j.

[20] K. Minakawa, A.J. McEvily, On crack closure in the near-threshold region, Scr. Metall. 15 (1981) 633-636. doi:10.1016/0036-9748(81)90041-7.

[21] T. Hanlon, E.D. Tabachnikova, S. Suresh, Fatigue behavior of nanocrystalline metals and alloys, Int. J. Fatigue. 27 (2005) 1147-1158. doi:10.1016/j.ijfatigue.2005.06.035.

[22] T. Leitner, A. Hohenwarter, W. Ochensberger, R. Pippan, Fatigue crack growth anisotropy in ultrafine-grained iron, Acta Mater. 126 (2017) 154-165. doi:10.1016/j.actamat.2016.12.059.

[23] T. Leitner, A. Hohenwarter, R. Pippan, Revisiting fatigue crack growth in various grain size regimes of Ni, Mater. Sci. Eng. A. 646 (2015) 294-305. doi:10.1016/j.msea.2015.08.071.

[24] A. Hohenwarter, R. Pippan, Fracture toughness evaluation of ultrafine-grained nickel, Scr. Mater. 64 (2011) 982-985. doi:10.1016/j.scriptamat.2011.02.007.

[25] T.L. Anderson, FRACTURE MECHANICS Fundamentals and Applications, CRC Press. (2017). doi:10.1201/9781315370293.

[26] M.T. Hutchings, P.J. Withers, T.M. Holden, T. Lorentzen, Introduction to the Characterization of Residual Stress by Neutron Diffraction, CRC press, 2005. 
[27] T.M. Holden, A.P. Clarke, R.A. Holt, Neutron diffraction measurements of intergranular strains in MONEL-400, Metall. Mater. Trans. A. 28 (1997) 2565-2576. doi:10.1007/s11661-997-0014-9.

[28] J. Filik, A.W. Ashton, P.C.Y. Chang, P.A. Chater, S.J. Day, M. Drakopoulos, M.W. Gerring, M.L. Hart, O. V. Magdysyuk, S. Michalik, A. Smith, C.C. Tang, N.J. Terrill, M.T. Wharmby, H. Wilhelm, Processing two-dimensional X-ray diffraction and small-angle scattering data in DAWN 2, J. Appl. Crystallogr. 50 (2017) 959-966. doi:10.1107/S1600576717004708.

[29] A.M. Korsunsky, K.E. Wells, P.J. Withers, Mapping two-dimensional state of strain using synchroton X-ray diffraction, Scr. Mater. 39 (1998) 1705-1712. doi:10.1016/S1359-6462(98)00385-6.

[30] P.J. Withers, M. Preuss, A. Steuwer, J.W.L. Pang, Methods for obtaining the strain-free lattice parameter when using diffraction to determine residual stress, J. Appl. Crystallogr. 40 (2007) 891-904. doi:10.1107/S0021889807030269.

[31] P.J. Withers, M.R. Daymond, M.W. Johnson, The precision of diffraction peak location, J. Appl. Crystallogr. 34 (2001) 737-743. doi:10.1107/S002188980101411X.

[32] C.A. Simpson, casimp/pyxe: XRD Strain Analysis (Version v0.9.3), Zenodo. (2019). doi:10.5281/zenodo.3381279.

[33] L. Malíková, V. Veselý, The influence of higher order terms of Williams series on a more accurate description of stress fields around the crack tip, Fatigue Fract. Eng. Mater. Struct. 38 (2015) 91-103. doi:10.1111/ffe.12221.

[34] M.L. Williams, On the Stress Distribution at the Base of a Stationary Crack, J. Appl. Mech. 24 (1957) 109-114.

[35] ASTM E647-15e1 Standard Test Method for Measurement of Fatigue Crack Growth Rates, ASTM International, West Conshohocken, PA, 2015. doi:10.1520/E0647-15E01.

[36] ASTM International, ASTM E399-17 Standard Test Method for Linear-Elastic Plane-Strain Fracture Toughness KIc of Metallic Materials, in: ASTM International, West Conshohocken, PA, 2017. doi:10.1520/E0399-17.

[37] S. Suresh, Fatigue crack deflection and fracture surface contact: Micromechanical models, Metall. Trans. A. 16 (1985) 249-260. doi:10.1007/BF02816051.

[38] C.A. Simpson, S. Kozuki, P. Lopez-Crespo, M. Mostafavi, T. Connolley, P.J. Withers, Quantifying fatigue overload retardation mechanisms by energy dispersive X-ray diffraction, J. Mech. Phys. Solids. 124 (2019) 392-410. doi:10.1016/j.jmps.2018.10.020.

[39] S. Zabeen, M. Preuss, P.J. Withers, Evolution of a laser shock peened residual stress field locally with foreign object damage and subsequent fatigue crack growth, Acta Mater. 83 (2015) 216-226. doi:10.1016/j.actamat.2014.09.032.

[40] X. HUANG, M. TORGEIR, W. CUI, An engineering model of fatigue crack growth under variable amplitude loading, Int. J. Fatigue. 30 (2008) 2-10. doi:10.1016/j.ijfatigue.2007.03.004.

[41] W. Zhang, C.A. Simpson, R. Pippan, P.J. Withers, The effect of R ratio on fatigue overload behaviour of ultrafine-grained nickel, (2019) (unpublished results).

[42] K. Walker, The Effect of Stress Ratio During Crack Propagation and Fatigue for 
2024-T3 and 7075-T6 Aluminum, in: Eff. Environ. Complex Load Hist. Fatigue Life, ASTM International, 100 Barr Harbor Drive, PO Box C700, West Conshohocken, PA 19428-2959, 1970: pp. 1-1-14. doi:10.1520/STP32032S.

[43] C.M. Ward-Close, A.F. Blom, R.O. Ritchie, Mechanisms associated with transient fatigue crack growth under variable-amplitude loading: An experimental and numerical study, Eng. Fract. Mech. 32 (1989) 613-638.

doi:10.1016/0013-7944(89)90195-1.

[44] W. Zhang, C.A. Simpson, P. Lopez-Crespo, T. Buslaps, R. Pippan, P.J. Withers, The effect of grain size on the fatigue overload behaviour of nickel, (n.d.) (unpublished results). 